\title{
Financing renewable energy: Who is financing what and why it matters ${ }^{\text {th }}$
}

\author{
Mariana Mazzucato ${ }^{\mathrm{a}}$, Gregor Semieniuk ${ }^{\mathrm{b}, *}$ \\ a Institute for Innovation and Public Purpose, The Bartlett, UCL, United Kingdom \\ b Department of Economics, SOAS University of London, United Kingdom
}

\section{A R T I C L E I N F O}

\section{Keywords:}

Renewable energy finance

Financial actors

Portfolio approach

Direction of innovation

Deployment

Technology risk

\begin{abstract}
A B S T R A C T
Successful financing of innovation in renewable energy (RE) requires a better understanding of the relationship between different types of finance and their willingness to invest in RE. We study the 'direction' of innovation that financial actors create. Focusing on the deployment phase of innovation, we use Bloomberg New Energy Finance (BNEF) data to construct a global dataset of RE asset finance flows from 2004 to 2014. We analyze the asset portfolios of different RE technologies financed by different financial actors according to their size, skew and level of risk. We use entropy-based indices to measure skew, and construct a heuristic index of risk that varies with the technology, time, and country of investment to measure risk. We start by comparing the behavior of private and public types of finance and then disaggregate further along 11 different financial actors (e.g. private banks, public banks, and utilities) and 11 types of RE technologies that are invested in (e.g. different kinds of power generation from solar radiation, wind or biomass). Financial actors vary considerably in the composition of their investment portfolio, creating directions towards particular technologies. Public financial actors invest in portfolios with higher risk technologies, also creating a direction; they also increased their share in total investment dramatically over time. We use these preliminary results to formulate new research questions about how finance affects the directionality of innovation, and the implications for RE policies.
\end{abstract}

\section{Introduction}

Mobilizing finance for investment and innovation in low-carbon energy is a key challenge for climate change mitigation (Dangerman and Schellnhuber, 2013; Grubb, 2014; Stern, 2015). Because cumulative carbon emissions determine the intensity of climate change, speed matters. Yet, fossil fuel investments continue to dwarf investments into renewable energy (RE). ${ }^{1}$ In 2013, RE received investments of less than USD 260 billion, which represented only 16\% of the USD 1.6 trillion in total energy sector investments (Fig. 1). Meanwhile, investment in fossil fuels in the power sector, where they compete directly with electricity from RE, rose by 7\% from 2013 to 2014 (UNEP and BNEF, 2015). Clearly, fossil fuels still dominate energy investment; therefore, a major concern in the transition to low-carbon energy provision is how to obtain enough finance to steer investments into the RE direction.

A closer look shows that the news is not all discouraging. Total funding for $\mathrm{RE}$ has been rising at a remarkable rate. According to
Bloomberg New Energy Finance (BNEF), the amount of RE finance along the entire innovation chain, from research and development (R \& D) for new technologies to asset finance for full-scale power plants, rose from USD 45 billion in 2004 to 270 billion in 2014 globally (Fig. 2). This represents a compound annual growth rate of $18 \%$. Moreover, in 2014, net investment into new capacity, as opposed to replacing depreciated assets, was twice as large for $\mathrm{RE}$ as it was for fossil fuels in the power sector; this trend is forecast to continue for the rest of this decade (International Energy Agency, 2015). Therefore, although investment in RE remains low relative to that in fossil fuels, the trajectory is a positive one.

The focus on achieving a greater amount of finance has diverted attention from what is being financed. Since finance flows towards concrete projects and firms, finance always-unless distributed uniformly-creates a direction towards areas and technologies that these organizations promote. This may result in a skewed distribution of investment in RE, so that some areas are over-financed, while others are

\footnotetext{
This paper has benefited from valuable feedback, suggestions, and enlightening conversation with many individuals. The authors would like to thank Abraham Louw, Edward

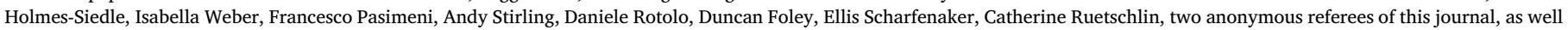

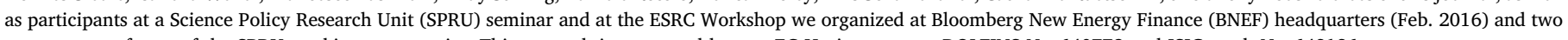
anonymous referees of the SPRU working paper series. This research is supported by two EC Horizon grants: DOLFINS Nr. 640772 and ISIGrowth Nr. 649186.

* Corresponding author.

E-mail addresses: m.mazzucato@ucl.ac.uk (M. Mazzucato), gs53@soas.ac.uk (G. Semieniuk).

${ }^{1}$ RE sources comprise solar radiation, wind, running water (hydro), marine waves and tides, biomass, and geothermal energy. Alternative low-carbon energy technologies are nuclear fission or fusion, as well as carbon capture and storage for fossil-fuel plants. The present paper only considers RE and further excludes large dams ( $>50$ MW capacity).
} 


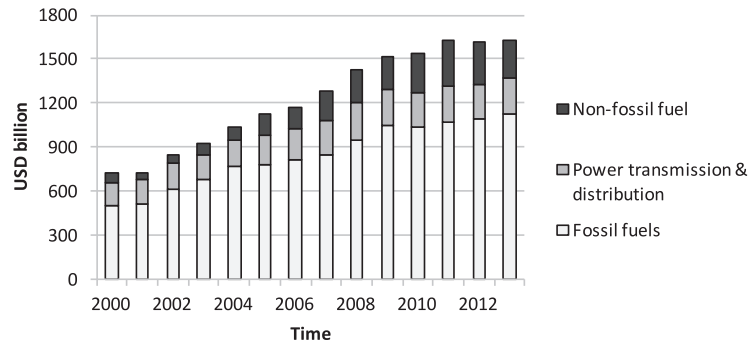

Fig. 1. Global investment into energy by destination. Source: (International Energy Agency, 2014).

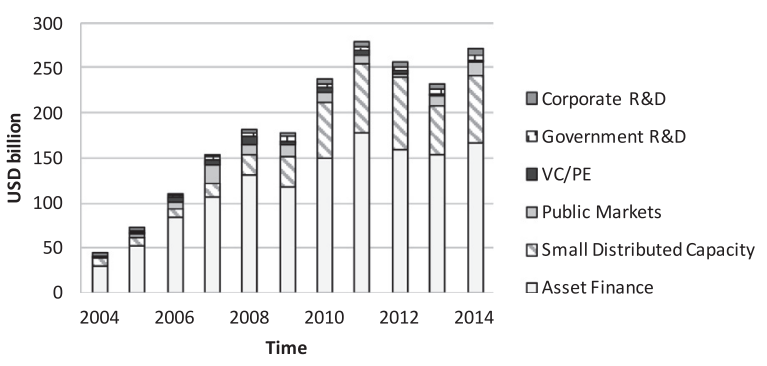

Fig. 2. Global investment into RE by area of finance. Source: (UNEP and BNEF, 2015).

under-financed (relative to average). Lack of attention on the relationship between finance and directionality is surprising because it is widely recognized that a diverse set of RE technologies is desirable, for at least two reasons. Firstly, with a wide portfolio, if innovation is unsuccessful in one area, not all eggs are in one basket (Grubler, 2012); secondly, a diversified energy supply increases resilience of the energy system and hence energy security (Stern, 2015; Stirling, 2010b).

There has been much research linking the research and commercialization phase of the innovation chain to specific financing needs. High-risk upstream research is widely understood to require public financing due to the characteristics of public goods (Arrow, 1962). Similarly, venture capital financing helps to solve the asymmetric information problem in the "Valley of Death" which requires carrying technologies from proof of concept to commercial scale (Auerswald and Branscomb, 2003). The public finance and venture capital that solve these "market failures" are shown in Fig. 2.

However, less studied are the diverse types of finance in the downstream phase of innovation: deployment and diffusion. And yet, more than two thirds of total RE finance went to asset finance for deployment of utility scale RE power plants, also shown in Fig. 2, and so can affect directions in innovation. ${ }^{2}$ Channels of influence work both directly through the finance committed favoring a certain technology, and indirectly through the effects of increasing returns to scale and learning by doing, where feedback loops from deployment to upstream innovation can create technology lock-ins (Arthur, 1989). Yet the literature on the 'directionality' of innovation, which has looked for example at the way that policy measures can affect directions of innovation either knowingly or unknowingly (Stirling, 2010a), has ignored the role of finance in this process.

In this paper, we link the literature on the directionality (and pathways) of innovation, with the literature on the relationship between finance and innovation. We study how different types of finance create directions in RE deployment. Our aim is to understand whether and how financial actors differ in their investments, thereby achieving a more granular understanding of the financing process and direction within it. We look at two types of directions: towards specific

\footnotetext{
${ }^{2}$ Small distributed capacity deals for residential and business rooftop solar modules of $<1$ MW make up another $25 \%$. A typical household rooftop solar module has a capacity of 1-4 kW. This study focuses on utility scale asset finance due to data availability.
}

technologies (such as onshore or offshore wind) and towards sets of more or less commercialized and hence risky technologies.

We consider the aggregate categories of "public" and "private" finance, which are typical distinctions in both theoretical and applied work about RE innovation (Popp, 2011; Veugelers, 2012). We also study 10 more disaggregated financial actors active in deployment (including private banks, public banks, private utilities, and public utilities). This perspective differs from the conventional focus on the sources of finance, e.g. different types of equity, debt and grants (Kerr and Nanda, 2015), and is connected to a growing body of literature (reviewed below) that demonstrates differences in financing behavior between financial actors.

Our disaggregated analysis is based on data from the BNEF database of deal-level global RE asset finance, from 2004 to 2014, as well as aggregate BNEF data on public banks. We distinguish financial flows from particular organizations to particular technologies. We draw on both ownership and industry classifications in the BNEF database to categorize financial actors. We update and correct the classification extensively using information from organizations' websites and reports. We also create a heuristic risk measure based on the literature on technology and market risk (Szabó et al., 2010), and Ernst and Young's (2015) Renewable Energy Country Attractiveness Index, which we applied to measure and compare the risk exposure that financial actors have, given their investment portfolio across technologies and countries. We analyze technology direction using entropy-based measures of portfolio balance, and risk direction by the share of finance flowing to high risk investments.

Our results suggest that not all sources of finance have the same impact on RE. Some financial actors skew their investment to a subset of technologies (e.g. public utilities towards offshore wind), while others spread their investments more evenly over a wide portfolio of competing technologies, creating technology directions. We also find that public actors not only invest in far riskier portfolios, influencing the risk direction, but also account for an increasing share of total investment.

Section 2 briefly reviews the literature on the relationship between finance and the direction of innovation, both generally and for RE. Section 3 introduces the data and our methods of analyzing differences in investment behavior. Section 4 discusses results on technological directions created through the skew of portfolios of private and public finance as well as 10 financial actors. Section 5 discusses results on risk directions through varying risk exposure of actors, and examines patterns of finance in four high-risk technologies. Section 6 concludes by discussing the implications of our results for climate change policy, and for future research on financing innovation. Two appendices provide details on the construction of our database and the risk index, respectively.

\section{Finance and energy innovation}

\subsection{Financial actors and innovation directions}

Joseph Schumpeter placed finance at the center of his theory of innovation, as providing the funds necessary for the entrepreneur to spring into action. However, he focused on only one type of finance: banks (Schumpeter, 1939, 114), and did not elaborate on the question of whether different financial actors' characteristics might impact what innovation is being financed, thus creating directions. The Miller-Modigliani theorem, which states that sources of finance (equity or debt financing from any actor) do not matter to firms and hence do not affect the real economy (Modigliani and Miller, 1959) has further detracted attention away from distinguishing between types of finance in innovation. In subsequent literature, the only types of actors typically singled out were "government" and "venture capitalists" (Hall, 2002). The job of the former was to overcome underinvestment in research due to the positive externality of knowledge (Arrow, 1962); the purpose of 
the latter was to overcome information asymmetries that led to underinvestment into product development by new firms or 'ventures' (Hall and Lerner, 2009). In this literature, finance takes a passive role regarding what is being financed.

More recent work has placed greater emphasis on different types of financial actors and how they may impact the characteristics of the firms and technologies they are financing. Thus, financing by the public sector also beyond the R\&D stage (Mazzucato, 2013) in areas like space, health and low carbon technology has resulted in the creation of whole new sectors, often through mission-oriented projects that were actively decided upon by those who provided the finance (Foray et al., 2012). In some countries, finance has been provided via innovation agencies like DARPA ${ }^{3}$ and/or tools for financing of firms via procurement, such as the SBIR ${ }^{4}$ in the USA. In countries such as Brazil, China, Germany, Japan, and in the European Union, important financial actors were public banks, providing patient finance for projects that aim to address "great challenges" such as climate change mitigation and adaption (Mazzucato and Penna, 2016; Schapiro, 2012) and promoting certain industries (Shimada, 2017; Griffith-Jones and Cozzi, 2016; Mazzucato, 2016b), jointly with a network of other public institutions (Shimada, 2017).

In private sector, certain actors were also pushing particular sectors or technologies; indeed, banks like Chemical Bank got their name from their role in financing the chemical sector (Mazzucato and Wray, 2015). But what gets financed may equally be influenced by what is neglected by certain actors: it has been noted that venture capital has often avoided very early seed investments, and has also been biased towards particular areas like IT and biotech, only recently getting interested in green-tech (Lerner, 2012). Some studies have examined how short-term speculative financial actors have affected science-based industries (Lazonick and Tulum, 2011; Pisano, 2006). Others have studied how interactions between different types of finance may affect sectoral development. For example, Owen and Hopkins (2016) looked at the way that the interactions between venture capital and the stock market, affected the biotechnology industry differently in the US and the UK. Therefore, the prevalence of one or another type of finance will privilege certain technological areas, certain levels of risk and consequently particular areas of innovation, and in the process induce directions into the innovation process. Yet, while the foregoing studies have examined the different characteristics of types of finance, they have not investigated how these characteristics may influence the direction of innovation.

Conversely, literature concerned with directions has paid little attention to the role of finance in setting these directions. The directionality literature (Stirling, 2010a, 2011) in innovation studies has stressed the importance of recognizing the multiple pathways and directions that innovation can take, so that policies explicitly recognize the forces influencing them, including the risk of sub-optimal policies and lock-in. This strand of literature has focused on the role of power relations, such as those embodied in public financing of innovation (e.g. the use of science advice and how decisions are made). However, it has ignored how the distribution and characteristics of private and public financial actors can affect the direction of change. Similarly, economic studies considering path-dependence in innovation (David, 1985) and the role of feedback effects in creating 'lock-in' (Arthur, 1989) have not included the way that financial institutions can affect this dynamic. The present study is motivated by this missing link between the type of finance and the directionality of innovation.

\footnotetext{
${ }^{3}$ Defense Advanced Projects Agency (Abbate, 1999). See discussion of DARPA's role in US innovation in Mazzucato (2013).

${ }^{4}$ Small Business Innovation Research Program, which provides early-stage finance to companies, through procurement (Keller and Block, 2013).
}

\subsection{Financial actors and direction in renewable energy}

The literature on RE financing, both modeling and empirical, has historically given more attention to sufficient investment in R \& D than to downstream financing of deployment (Popp, 2011; Sagar and van der Zwaan, 2006). Yet, a key gap identified in RE more recently is the lack of finance for downstream capital-intensive high-risk projects (European Commission, 2013; Veugelers, 2012; Zindler and Locklin, 2010), kindling a growing literature that studies actors in the deployment of RE technologies. One strand focuses on different risk appetites of types of finance. For example, Ghosh and Nanda (2010) have argued that the capital required for asset finance of the capital intensive RE power plants is typically an order of magnitude larger than that which venture capitalists have been willing to supply for technology development (see also Gaddy et al., 2016), and too risky for banks (Kalamova et al., 2011). Evidence for differences in risk perception between individual investors has been furnished for a sample of European investors by Masini and Menichetti (2012). While these studies do not distinguish types of financial actors, Bergek et al. (2013) studied three types of power plant builders in Sweden - utilities, farmers, cooperatives - and highlighted how different builder types may have various nonprofit maximization objectives that influence their investment choices. The results connect with conceptual work by Langniss (1996), who identified six financial actors (anonymous, industry, large utility, house owner, municipality, energy community) and discussed how each type's appetite for risk varies with their motives for investment.

Another strand focuses on the impact of public policies on private deployment finance. Studies that used aggregate data to examine the impact of innovation policies by government aimed at upstream innovation on private RE deployment (Johnstone et al., 2009; Popp et al., 2011), and at private downstream activities (Eyraud et al., 2013) found that these policies do mobilize private finance. Using micro data at the asset deal level (mostly from BNEF, as in the present study), public policies were found to mobilize finance from institutional investors (Polzin et al., 2015) and to have a positive effect on cross-border merger and acquisition activity (Criscuolo et al., 2014). Certain types of policies are more conducive to investment in RE innovation than others (Veugelers, 2012), and may induce varying amounts of venture capital investments into RE companies (Criscuolo and Menon, 2015). Only two studies have distinguished direct public investments (Cárdenas Rodríguez et al., 2014; Haščič et al., 2015). They found that both public investments and policies have a significant positive impact on private investment. In addition, Cárdenas Rodríguez et al. (2014) showed that direct public investments are taking place for those technologies, where other public policies have had little effect on mobilizing private finance.

As for directions, the directionality literature has considered the energy sector, but focused on the interplay of agency and structure and the influence of power without distinguishing finance (Stirling, 2014). Meanwhile in economics, discussion of the direction of technical change in energy (distinguishing fossil and RE directions) incorporates an influence of financial actors neither in the phase of R \& D (Acemoglu et al., 2016) nor in that of deployment (Jaffe et al., 2005).

\subsection{Our study in the context of the literature}

In sum, certain types of investors have been more likely than others to provide the capital-intensive, high-risk, patient finance needed to achieve innovation, and there is some insight into differences between public and private actors. However, the patterns of finance in deployment - who finances, and what - for RE technologies are not well understood. Although there are conceptual arguments for why different financial actors may display varying behavior, and for why some areas or technologies may be financed more than others, creating directions, quantitative empirical studies have not followed up and investigated these hypotheses at a disaggregated level. We know that the landscape of $\mathrm{RE}$ finance consists of a heterogeneous set of actors (Buchner et al., 


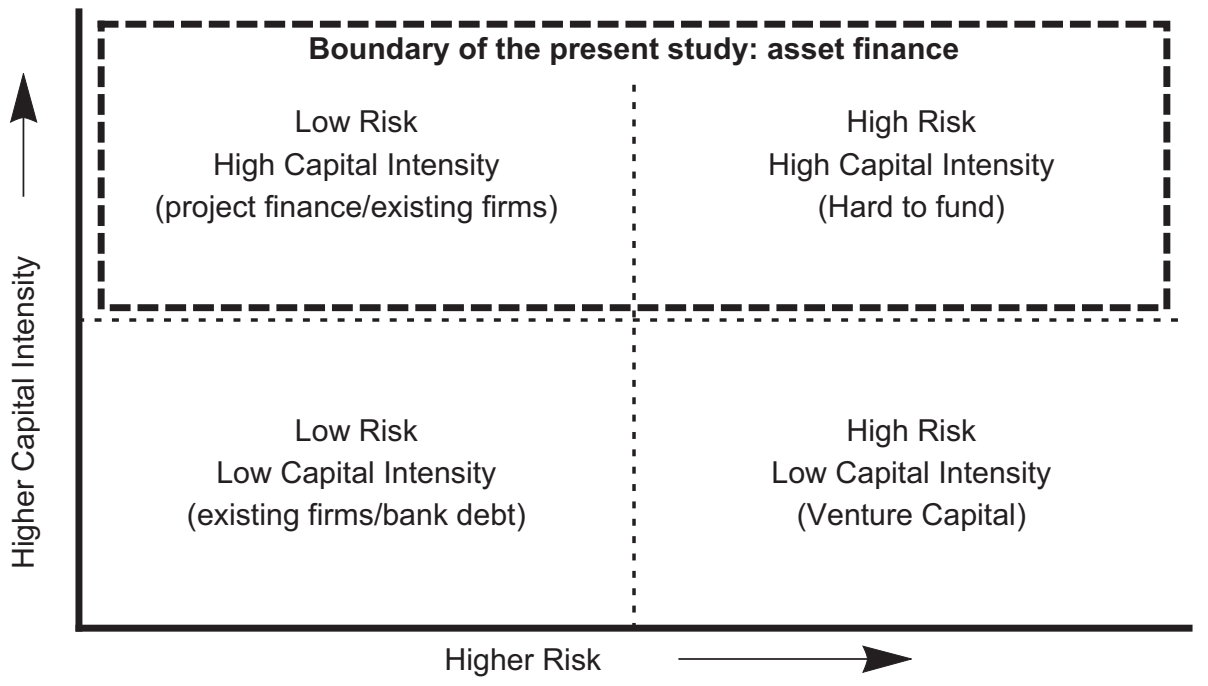

Fig. 3. Risk-capital intensity classification of RE finance. (Adapted from Ghosh and Nanda, 2010.)
2015), but we do not know much about their role and how this might affect the direction of the evolution of RE.

The present paper attempts to fill this lacuna by studying the heterogeneity in RE financing decisions of different public and private financial actors and how these affect the technology and risk directions of innovation. For technology directions, since there is no evolved theory beyond the public/private divide regarding how financial actors should differ in favoring certain areas, we simply investigate the hypothesis that financial actors differ in their portfolio composition. The technology classification is imposed by our data. For the risk direction, Ghosh and Nanda (2010) proposed a classification of RE investments that comes closest to associating particular financial actors with particular phases in RE innovation based on expert interviews. Fig. 3 is an adaptation of Ghosh and Nanda's results: a division of labor in RE financing whereby the development of new, high-risk technologies that require small amounts of capital is funded by venture capital, while the deployment of low-risk technologies occurs via existing energy firms with bank debt through project finance. Ghosh and Nanda left the nature of financial actors carrying out high-risk technology deployment unclear but suggested that not all types of finance are to be found in the upper right quadrant. With our focus on the capital intensive deployment phase, we focus on the upper to quadrants and investigate the hypothesis that only a subset of actors is active in financing 'high-risk, high capital intensity' technologies.

Our goal is to better understand whether financial actor types show different investment patterns and how the characteristics of finance can affect the nature of investment patterns. Given the rising number of RE investments, we hope that studying this dynamic will move the policy question beyond the quantity of finance and more towards the quality.

\section{Data and methods}

\subsection{Data}

Our study is global in scope, covering the actor and technology patterns of asset finance for the planet's RE power plant deployment over the period 2004-2014. ${ }^{5}$ We use a rich dataset that we constructed from three different BNEF asset finance databases (of sponsor, lead arranger, and syndicated lender participations), and one database with organization characteristics (BNEF, 2015b). We improved the quality of the data by adding information from a dataset on aggregate state bank finance (BNEF, 2014a) and from extensive research of publicly

\footnotetext{
5 The data comprise 39,135 participations in 28,395 unique asset finance deals. BNEF estimates that coverage is upward of $80 \%$ of all deals in the period covered.
}

available sources (news or organizations' reports) about specific deals and organizations. Our final dataset presents asset finance for utility scale ( $>1 \mathrm{MW}$ capacity) power generation in terms of individual investors' contributions to individual deals for newly built RE power plants. Small distributed capacity must be excluded as there is no deallevel data. The details of the dataset construction are provided in Appendix A.

We distinguish investment flows to 11 different technologies, which are listed with their shares in Table 1. Cumulatively, half of asset finance supported onshore wind power plants, followed by $18 \%$ for crystalline silicon photovoltaic (c-Si PV) module power plants, which reveals a clear direction of finance towards those technologies. All other technologies received $<10 \%$ of total investment each. We disaggregated technologies more than typical analyses, which highlights the heterogeneity in terms of finance received between technologies within broader technology areas, such as c-Si PV and other PV technologies.

We distinguish 10 different financial actors: six private and four public, and an 11th unclassified actor. Private investors are split into three non-financial and three financial types that differ by their function with respect to the energy sector. The non-financial types are energy firms (component manufacturers, project developers, and a few fossil fuel firms with investments in RE); utilities; and all remaining non-financial companies, which we labeled "industrials". ${ }^{6}$ The financial types are commercial banks; non-bank financial firms (such as private equity firms and pension funds), which we labeled institutional investors; and not-for-profit investors such as foundations or co-operatives. ${ }^{7}$ We split the public investors into government agencies (which include a small number of research institutes) and three types of statecontrolled or state-owned entities that match their private counterparts: state banks, which include state-owned investment funds; state-owned utilities; and other non-financial state-owned companies. ${ }^{8}$ Finally, we

\footnotetext{
${ }^{6}$ Seventy-seven percent of the investments in the dataset made by energy firms come from companies whose main market exposure is in RE; the remainder are typically fossil energy companies. Only $14 \%$ of investments in the dataset were made by companies classified in other sectors are from those whose main market is in RE; these are biofuel producers that are not classified in the RE sector but with 'industrials'.

7 The non-profit investors include a small number of non-financial cooperatives that are able to finance large projects included in asset finance.

${ }^{8} \mathrm{~A}$ company is state-controlled if it is stock market-listed but the government or its agencies retain a controlling stake. To be state-controlled we used the conservative estimate of share ownership of $>50 \%$. An example is the French utility EDF, where the state owned $84.9 \%$ of the share as of December 2015 (EDF, 2016, 487, Table 7.3.8). Often, governments retain control with much smaller shares, by having preferential voting rights or golden shares. We use the term "state-owned" to include companies that are state-controlled.
} 
Table 1

Technologies, ranked by share of investment received in 2004-2014.

\begin{tabular}{lll}
\hline & Technology & Share of finance received, as a \% \\
\hline 1 & Onshore wind & 49.2 \\
2 & Crystalline silicon PV (c-Si PV) & 18.1 \\
3 & Biomass and waste & 8.5 \\
4 & Conventional or first-generation biofuels & 6.7 \\
5 & Offshore wind & 6.7 \\
6 & Solar: Concentrating Power (CSP) & 3.7 \\
7 & Other PV (thin film, CPV) & 2.5 \\
8 & Small hydro & 2.2 \\
9 & Geothermal & 1.4 \\
10 & Advanced or second-generation biofuels & 0.7 \\
11 & Marine & 0.2 \\
\hline
\end{tabular}

added investments by unclassified investors to the "private investors" category where necessary.

Any interpretation of the data must account for substantial amounts of missing data with respect to investors' characteristics, and yet these are the most comprehensive data available that distinguish the actors behind finance flows. We improved data quality as follows. Firstly, shares of actors were missing, so unless we were able to find shares from publicly available data - for example, from European Investment Bank reports - we imputed shares by distributing asset value equally across participants. ${ }^{9}$ Secondly, there were significant gaps and errors in the ownership and industry classification of actors. We manually added financial actor information for several dozen unclassified investors based on information found on organization websites and corrected the classification for over 100 already classified organizations. ${ }^{10}$ Even after these corrections, however, $15 \%$ of all invested funds could not be attributed to any financial actor. Thirdly, lenders are underrepresented because many deals do not report their debt sources; in such cases, BNEF attributes the entire deal to the sponsors who own equity in the project. This can be verified with aggregate RE finance statistics that show state banks invest significantly more in asset finance than the deal-level data reveals (BNEF, 2014a). Accounting for these investments doubles the share invested by the state banks (and subtracts an equal percentage from other investors that benefit from this debt finance). ${ }^{11}$ Because the deal-level dataset omits these important creditors, the detailed portfolio analysis cannot make use of this correction and inevitably overstates the role of (mostly private) sponsors. ${ }^{12}$ With these caveats in mind, Table 2 lists financial actors with their cumulative shares.

\subsection{Methods}

We characterized differences in the RE portfolios in which financial actors invest. We distinguished between three dimensions - size, portfolio skew, and risk-taking - which translate into two directions. Skew provides a measure of the technological direction towards a subset of

\footnotetext{
${ }^{9}$ Details in Appendix A.

${ }^{10}$ Corrections included changing the $62 \%$ government-owned State Bank of India from a private "quoted company" to a state-owned enterprise and changing the industry classification of the World Bank Group from the "consumer discretionary" sector to the "financials" sector.

${ }^{11}$ We estimated that $15 \%$ of the state banks' undisclosed portfolio finances large hydro, based on reported large hydro investment volumes (Louw, 2013), and that $70 \%$ of the remaining portfolio finances new-build, large-scale assets, as opposed to refinancing or small-scale investment. The resulting figures tally with the KfW's reported RE finance provided for businesses (KfW, 2014, 77, 2015, 99).

12 For instance, there are 6194 equity financing entries for China in deals that do not show any debt and sum to USD 308 billion. However, the state bank deployment data shows that this equity volume veils around USD 25 billion in undisclosed RE loans by the China Development Bank during 2007-2013 alone. When aggregating investments into public and private categories, we added undisclosed state bank investments to the public total and subtracted it from the unclassified investors, the remainder of whose investments are counted in the private category.
}

Table 2

Financial actors' share in cumulative finance provided over the period 2004-2014.

\begin{tabular}{lll}
\hline Category & Actor (and abbreviation) & $\begin{array}{l}\text { Share of finance provided in } \\
\%\end{array}$ \\
\hline \multirow{2}{*}{ Private } & Energy firms & 11.3 \\
& Private utilities (Priv. utilities) & 17.1 \\
& Industrials & 10.4 \\
& Commercial banks (Banks) & 11.7 \\
& Institutional investors & 7.2 \\
Public & Charities/not for profit (Charities) & 0.8 \\
& State banks & $15.0^{\mathrm{a}}$ \\
& State utilities & 12.6 \\
& Other state corporations (State & 4.4 \\
& corps) & 2.5 \\
& Government agencies (Gov. & $7.6^{\mathrm{a}}$ \\
& agencies) &
\end{tabular}

a After corrections using aggregate state bank statistics (BNEF, 2014a). State banks provide $7.6 \%$ of disclosed deals and $15 \%$ are provided by unclassified investors.

technologies in the portfolio of an investor. Weighted by its size, this translates into a technology direction of the aggregate portfolio. Risktaking provides a measure of the portfolio's risk direction to high-risk technologies. We also documented the consequence for technologies of portfolio differences by analyzing how technologies differ in the amounts of investments they receive from all actors, and from what distribution of actors.

In order to delineate portfolios, we subdivided the investment flow, $x$, into 11 technologies indexed by $j=1, \ldots, 11$ over which a portfolio can spread. To delineate investors, we take the 11 functional financial actors indexed by $i=1, \ldots, 11$ explained in the data description. In some cases, we summed over private and over public financial actors to analyze investor categories. In the dimension of time, we divided the dataset into three periods: pre-crisis (2004-2008), "Great Recession" or crisis (2009-2011), and post-crisis (2012-2014). Where useful, we distinguished between annual investment flows. Then the size of the investment flow of actor $i$ in technology $j$ during time $t$ is denoted as $x_{i j t}$.

To measure skew, we considered shares of investment and deployed standard tools from information theory, which are used widely in analysis of diversity and inequality. Assuming that all technologies are equally different from each other, we identified the skew in the portfolio of actor $i$ by calculating its Shannon entropy, $H$ (Shannon, 1948), which is defined as

$H_{i t}=-\sum_{j=1}^{J} p_{i j t} \log p_{i j t}, \quad i=1, \ldots, I, t=1,2,3$

where $p_{i j t}=\frac{x_{i j t}}{x_{i t}}$ is the share of investment flowing to technology $j$ in $i$ 's portfolio during time period $t$ and $\sum_{j=1}^{J} p_{i j t}=1$ for given $i$ and $t$. The Shannon entropy is maximal if the share of investment in each technology is equal, and minimal if all investment goes into only one technology. Hence, calculating the entropy of a portfolio gives an inverse measure of a financial actor's direction of investment across technologies: zero entropy translates into investment directed only toward one technology, maximum entropy translates into the greatest balance of investment between technologies and an absence of any direction. Between these extremes, a lower entropy signifies that an actor directs its investment toward particular technologies, without revealing which technology or technologies it favors. Since entropy is independent of portfolio size, it can be compared across actors. We further divided $H_{i t}$ by maximum entropy $H^{\max }=\log \frac{1}{11}$, where each of the 11 technologies receives an equal share of investment. The quotient $H_{i t}^{n}=\frac{H_{i t}}{H^{\max }}$, is normalized entropy, $H^{n}$, and lies on the interval zero-one. Maximum entropy has been used in finance theory to evaluate optimal or 'maximum entropy' diversification given certain constraints on investments (Bera and Park, 2008). We note the analogy in the measure, 
but emphasize that we evaluate observed historical diversification across multiple individual units within one financial actor rather than computing decision rules for individual investor portfolios.

We also calculated the direction of the total investment, $H^{I}$, by considering the share technologies have received in the market portfolio, $p_{j t}$. This gives the aggregate direction, but may cancel out individual portfolio directions. Since we would also like to know the behavior of the sum of financial actor directions, rather than the pooled direction, we expanded on entropy with a measure used in the inequality literature. In particular, studies of occupational segregation following (Theil and Finizza, 1971) have used entropy-based measures such as the Theil Index to evaluate the contribution of individual units to city or industry-wide segregation. With financial actors instead of indicators such as race or gender, and technology instead of occupation, the Theil Index, $T$, can be readily used for summing over financial actors' directions.

$T_{t}=-\frac{1}{H_{t}^{J}} \sum_{i=1}^{I} p_{i t} \sum_{j=1}^{J} p_{j t} p_{i j t} \log p_{i j t}, \quad t=1,2,3$

where $\mathrm{p}_{i t}$ is the share of financial actor $i$ in total investment that weights the financial actor's direction, and technology skew is weighted by the share the technology receives in total investment, $p_{j t}$. The index is normalized by dividing through its maximal value $H^{J}=\sum_{i=1}^{I} p_{i t} \log p_{i t}$, which assumes no direction within investor portfolios. Again, a value of one means no direction within any investor portfolio, whereas zero means all financial actor portfolios invested in only a single technology. The Theil Index sums over the directions of financial actors within the total portfolio, enabling a comparison of directions over time weighted by portfolio size.

Finally, flipping $i$ and $j$ indices in Eqs. (1) and (2), we also computed the normalized entropy of investment reaching a technology $\left(H_{j t}{ }^{n}\right)$ that reflects how concentrated investors are in financing that technology's deployment; the overall concentration of investors using overall entropy $H^{J}$; and the technology Theil Index, characterizing the investor concentration summed over technologies. To analyze the importance of financial actors in individual technologies further, we also computed the contributions of investors to growth in these technologies, $g_{i j t}=\frac{x_{i j t}-x_{i j(t-1)}}{x_{j(t-1)}}$.

This leaves a measure of risk. A definition of risk is inherently subjective (Fischhoff et al., 1984), yet here we consider the comparatively well-defined financial risk of return to investors on the assets they financed. The risk of individual RE assets depends on factors specific to the power plant site, information of the investors about contractors, and many other undisclosed factors, and is subject to the investors' own perception (Masini and Menichetti, 2013). One expression of these idiosyncratic, undisclosed, and subjective factors is the required rate of return for corporate finance decisions, the internal rate of return for project finance sponsors, and the interest rate for loans. Knowledge of these data would allow a detailed risk analysis after controlling for national differences in capital markets, country risk, and interest rates.

For our asset finance data, however, the rates of return or interest remain undisclosed. What we do know is the technology financed up to a certain level of detail and the country of investment. There are 42 different technological categories in the dataset and 164 countries, permitting the use of risk categories of "technology", "market," and "country" risks. We used the common method of constructing a risk index by identifying risk in each category and aggregating it into a onedimensional index (MacKenzie, 2014). We first created a unidimensional index of technology and market risks, which are often positively correlated (Hartmann and Myers, 2001), of "low-risk", "medium-risk," and "high-risk" investments. We then adjusted the riskiness for the country risk, and assumed that individual asset finance risk deviations are distributed as white noise. The resulting risk measure is relative with reference to the dataset: the risk of investing in one asset is high relative to that of investing in another.
Technology risk can be defined as the "technology problems" associated with the lack of knowledge about the parameters that determine "performance, cost, safe operating latitudes, or failure modes" (Hartmann and Lakatos, 1998, 32). As a technology is deployed more often, the data on frequency and severity of technical failure grows and hence uncertainty regarding technology problems falls. One important source of information is whether power plants live for their projected lifetime (often 20-25 years with RE power plants), hence young technologies where few or no power plants have been completely depreciated yet have a higher risk. Our estimates were informed by a review of assessments of the technological riskiness of our 11 technologies in the scientific literature.

Market risk for assets is typically defined as a dispersion of returns around mean (expected) returns (Markowitz, 1952), the sources of which comprise interactions of operational, financial and asset valuation aspects operating at different time scales in energy markets (Denton et al., 2003). Absent return figures, we relied on estimates of market risk based on growth in market share (Tietjen et al., 2016). We use the estimates in Szabó et al. (2010) for 2009 and extend them in time based on relative levels in levelized cost of electricity (LCOE) per unit of energy produced. LCOE divides the total capital expenditure, cost of capital, cost of fuels (for biomass), and maintenance cost by the expected units of electricity produced over the lifetime of the power plant. We assumed that a difference in LCOE favors the cheaper technology in capturing market share and hence having a lower market risk. Our estimates were informed by annual and quarterly time series estimates of LCOE for each technology.

The analysis of the technology risk literature review and LCOE estimates for each technology are in Appendix B. Table 3 summarizes the resulting unidimensional measure of historical relative risk. Most technologies display a stable low, medium, or high level of risk over time, but the risk of PV solar energy technologies (numbers 3 and 4) falls during the period. Albeit heuristic, our characterization of risk is more thorough than any we have found in the literature.

Country risk is defined as the regulatory risk about continuation of government policies that influence the profitability of RE asset finance and other country-specific financial risks. In this category, we have relied on the comprehensive evaluation in the Renewable Energy

Table 3

Technology risk classifications 2004-2014.

\begin{tabular}{|c|c|c|c|}
\hline & Technology & Sub-technology & Risk \\
\hline \multicolumn{4}{|c|}{ Wind } \\
\hline 1 & Onshore & & Low \\
\hline 2 & Offshore & & High \\
\hline \multicolumn{4}{|c|}{ Solar } \\
\hline 3 & $\begin{array}{l}\text { Crystalline silicon } \\
\text { (PV) }\end{array}$ & & $\begin{array}{l}\text { High (2004-2006), medium } \\
(2007-2009), \text { low } \\
(2010-2014)\end{array}$ \\
\hline \multirow[t]{2}{*}{4} & Other PV & Thin film PV & $\begin{array}{l}\text { High (2004-2009), medium } \\
(2010-2014)\end{array}$ \\
\hline & & $\begin{array}{l}\text { Concentrator PV } \\
\text { (CPV) }\end{array}$ & High \\
\hline 5 & $\begin{array}{l}\text { Concentrated Solar } \\
\text { Power (CSP) }\end{array}$ & & High \\
\hline \multicolumn{4}{|c|}{ Biofuels } \\
\hline 6 & $\begin{array}{l}\text { First-gene-ration } \\
\text { fuels }\end{array}$ & & Low \\
\hline 7 & $\begin{array}{l}\text { Second-gene-ration } \\
\text { fuels }\end{array}$ & & High \\
\hline \multicolumn{4}{|c|}{ Other technologies } \\
\hline 8 & Biomass and waste & $\begin{array}{l}\text { Incineration } \\
\text { Other biomass } \\
\text { technologies }\end{array}$ & $\begin{array}{l}\text { Low } \\
\text { Medium }\end{array}$ \\
\hline 9 & Geothermal & & Medium \\
\hline 10 & Marine & & High \\
\hline 11 & Small hydro & & Low \\
\hline
\end{tabular}


Country Attractiveness Index (RECAI) published by Ernst and Young (2015) for every quarter from 2004 to 2014 for 40 countries; the indicator is defined on an interval, making it possible to distinguish between more than only three categories. To account for regulatory risk, we represented low, medium, or high risk from Table 3 for any individual asset, $\mathrm{n}$, by the numbers $r_{n}=1 / 6,1 / 2,5 / 6$ and added the country risk score, which ranges from $-1 / 6$ to $+1 / 6$. More detail about the RECAI and how it is used here can be found in Appendix B. Letting country circumstances shift risk only by a fraction of the spectrum reflects the view that policy is not the only variable determining the risk of an investment (Wüstenhagen and Menichetti, 2012). Hence, any actor's portfolio has a risk exposure of between 0 (low) and 1 (high), depending on the share it invests in high-risk and low-risk technologies in certain countries. The risk exposure $R$ of the investment portfolio of type $i$ for year $t$ is calculated as the weighted average

$R_{i t}=\frac{1}{x_{i t}} \sum_{n=1}^{N}\left(r_{n t} x_{i n t}+c_{n t}\right), \quad i=1, \ldots, 10, \quad t=2004, \ldots, 2014$

where $n$ is the index of assets invested in, $r_{n t}$ the technology and time dependent risk indicator, weighted by the flow of finance invested by financial actor $i$ into asset $n, x_{i n t}$, and shifted up or down by the time varying country risk score $c$. While this is only a heuristic approximation, the ordinal nature of the measure makes it robust: there is no dispute that investment in an onshore wind asset in a country with stable policies is less risky, on average, than investment in relatively untested offshore technology in a country prone to swings in its policy support; financial actors that invest most of their funds offshore should have a higher risk exposure than those focusing on onshore investments.

\section{Differences in portfolio size and skew}

\subsection{Investor category size}

We begin the discussion of our results with differences in size between public and private investor categories. Although splitting asset finance into public and private figures hides variety within each category, and we ultimately aim to distinguish financial actors more finely, the public-private split is useful for two reasons. First, discussions about RE finance are largely informed by market failure theory, which associates the public sector mainly with research and development. The split of deployment finance into private and public investments checks whether the public also has a role downstream. Second - perhaps due to the sway market failure theory holds over the analysis of innovation finance - the elementary statistic of a split of the share of public investments in asset finance is not available for this timespan, not even in the flagship publications of global RE finance trends (Buchner et al., 2015; UNEP and BNEF, 2015).

The left-hand panel of Fig. 4 shows the evolution of annual total investment of public and private investor categories over time. Both time series grow rapidly, then level off. However, the public series grows for longer, reflecting a dramatic shift that took place from an asset finance market supplied in 2004 to $90 \%$ by private finance to a market with almost equal splits between private and public sources in 2014. The decisive year was 2009 , when public investment rose while private investment fell due to the impact of the Great Recession, which led to a stable overall asset finance, but a sea change in its composition. In other words, since 2009 , public actors have supplied well over a third of global RE asset finance, and in some years almost half.

Although our analysis focused on the global level, we singled out China, since the most important change over time in total RE finance was that country's rise. ${ }^{13}$ From 2004 to 2014, China's share in asset

\footnotetext{
${ }^{13}$ In ongoing further research we are considering national patterns and how they are influenced by national policies.
}

finance rose from 8 to $46 \%$. This poses a challenge for the analysis of financial actors because China's company ownership structure is rather different from that of the other countries in the dataset. China has an especially large proportion of state-owned enterprises; therefore, the results for the world may be skewed towards the Chinese case. For that reason, we recalculated the public and private investments, excluding asset finance made in China, in Fig. 5, right panel. This panel shows that although the volume of public investments outside China caught up less with private ones from 2009 onwards, public sources accounted for no $<30 \%$ of total investments in every year after 2008. In particular, public sources recorded a growth of $230 \%$ from 2006 to 2014, while private investments shrunk by $12 \%$ over the same period. As a result, even in the more private actor-oriented economies of the OECD, which comprise most of the investment in the right hand panel of Fig. 4, public sources of finance have been playing a pivotal role in stabilizing the investment volume.

These results are striking because they contradict the theoretical view that downstream innovation phases like deployment are outside the scope of direct public intervention. The empirical split of finance between public and private actors after 2008 is similar to that for R \& D in the RE sector (BNEF, 2015c). The prescription in market failure theory for public monies to finance only upstream R \& D is far removed from reality. However, these results also show that without massive increases in public spending, investment in RE would have been lower in 2014 than before the financial crisis. Needless to say, it is ultimately the cumulative investment rather than the level of investments in a particular year that matters. Yet, except for 2011, no year saw higher private investment than 2008, and the private high point in 2011 must be seen in the context of government stimuli, which we discuss in Section 5 . Hence, in spite of widespread energy sector privatization and public sector austerity, public investors are playing an increasingly important role in financing the deployment of RE technologies and are the only reason that $\mathrm{RE}$ asset finance has experienced any growth at all between the onset of the 2008 financial crisis and 2014 .

\subsection{Financial actor size and skew}

At the level of financial actors, we analyze both size and portfolio skew, but reduce time to three periods in order to reduce complexity and average over lumpy individual investments. These periods are: prefinancial crisis, crisis with government stimuli, and post-stimulus. Table 4 shows the shares in total investment and the portfolio entropy of each actor. The last two rows display total investment, entropy of the global portfolio, and the Theil Index. All figures are expressed in percentages. Looking first at shares, financial actors all had different shares but never $>20 \%$. Energy companies, institutional investors, and both commercial and state banks had stable shares, while all other types saw growth or decline by more than one-third of their first period's finance flow. However, while the remaining private investors' relative portfolio size declined, public investors increased theirs, causing public investors as a category to grow. Indeed, while all private financial actors had smaller shares in the post-crisis than in the pre-crisis period, all public financial actors had larger ones. Moreover, all public actors grew their share between any two periods, with the only exception being government agencies, which reduced their crisis stimulus activity (more below). These results not only show how financial actors differed in their investment size and its evolution over time, but also that, for companies in the utilities industry, it makes a great difference whether they are privately or publicly owned, that is, who does the financing (the qualitative result holds when excluding investments made in China). The same is true for commercial and state banks once the missing state banks investments are accounted for, doubling the state bank share to almost $20 \%$ in the third period. Hence, whether an organization is publicly or privately owned has an important bearing on the evolution of financing volume, regardless of the exact functional actor type. 

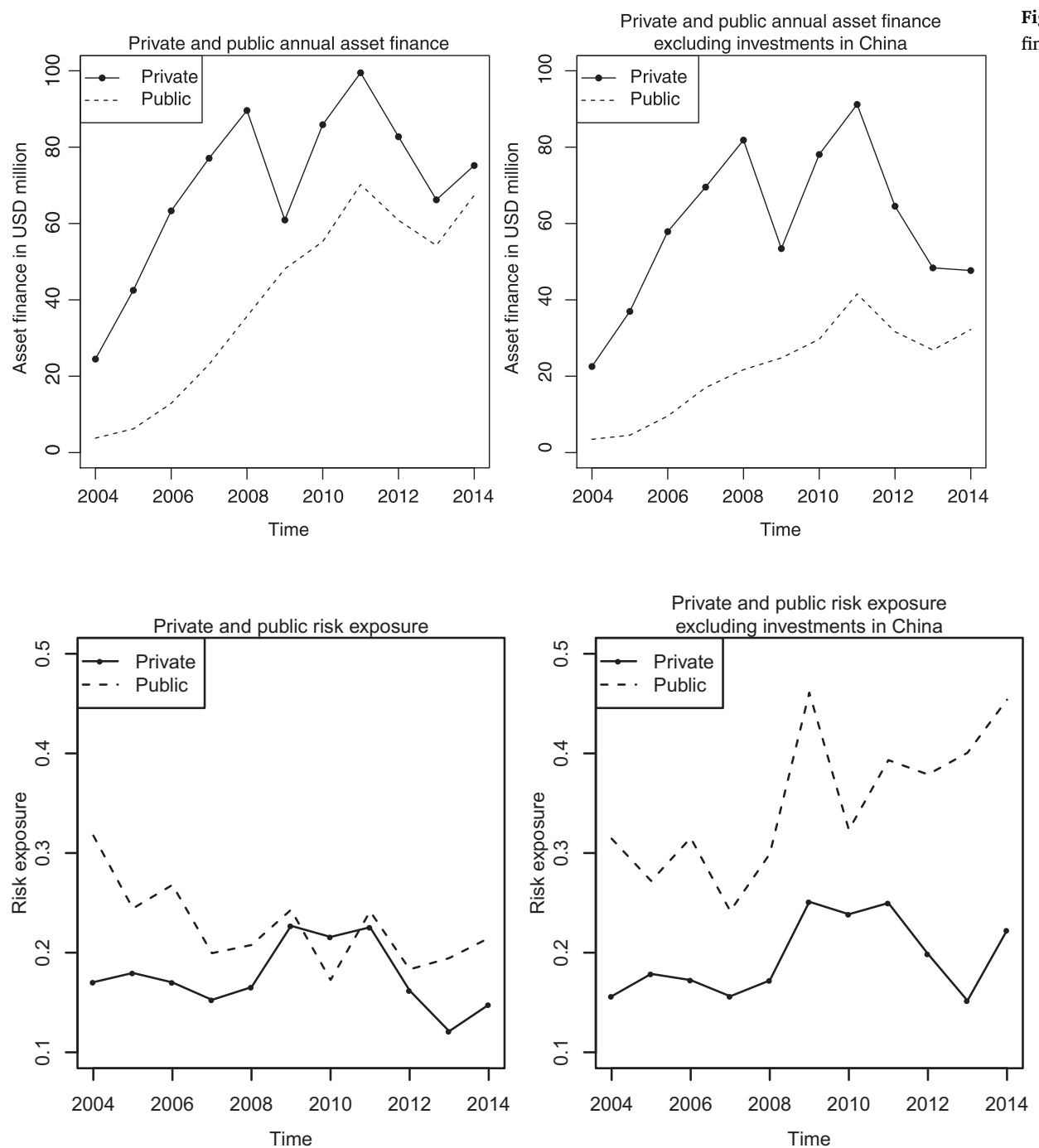

Fig. 4. Volume of annual public and global private asset finance (left panel) and excluding China (right panel).
Fig. 5. Exposure to risk of annual public and private asset finance for global investments (left panel) and excluding investments made in China (right panel).
Table 4

Share in total investment, entropy of portfolio of each financial actor, and total investment, total "portfolio" entropy and Theil Index for three periods. All figures except total investment are expressed in percentages.

\begin{tabular}{|c|c|c|c|c|c|c|}
\hline \multirow[b]{2}{*}{ Financial actor } & \multicolumn{2}{|c|}{ 2004-2008 } & \multicolumn{2}{|c|}{ 2009-2011 } & \multicolumn{2}{|c|}{$2012-2014$} \\
\hline & Share & Entropy & Share & Entropy & Share & Entropy \\
\hline Energy firms & 12.0 & 57.6 & 10.6 & 63.2 & 11.6 & 51.9 \\
\hline Priv. utilities & 18.0 & 43.4 & 19.6 & 59.9 & 13.7 & 46.9 \\
\hline Industrials & 14.1 & 64.5 & 9.8 & 77.9 & 9.0 & 61.8 \\
\hline Banks & 11.4 & 54.9 & 10.3 & 64.5 & 11.3 & 62.7 \\
\hline $\begin{array}{l}\text { Institut'l } \\
\quad \text { investors }\end{array}$ & 6.2 & 62.3 & 4.9 & 75.1 & 6.9 & 63.3 \\
\hline Charity & 1.2 & 66.3 & 0.9 & 74.9 & 0.4 & 64.7 \\
\hline State banks & 7.5 & 66.3 & 8.0 & 76.8 & 9.2 & 70.9 \\
\hline State utilities & 6.4 & 47.8 & 14.1 & 34.8 & 16.7 & 43.8 \\
\hline $\begin{array}{c}\text { Other state } \\
\text { corps }\end{array}$ & 2.0 & 49.2 & 5.0 & 63.9 & 6.1 & 51.9 \\
\hline Gov. agencies & 1.6 & 75.8 & 3.9 & 86.4 & 1.8 & 77.5 \\
\hline Unclassified & 19.5 & 68.1 & 12.7 & 68.8 & 13.1 & 53.5 \\
\hline Total & $\begin{array}{l}\text { USD } \\
379 b n\end{array}$ & 66.8 & $\begin{array}{l}\text { USD } \\
420 \mathrm{bn}\end{array}$ & 70.3 & $\begin{array}{l}\text { USD } \\
407 \mathrm{bn}\end{array}$ & 60.5 \\
\hline Theil Index & & 12.0 & & 11.5 & & 13.0 \\
\hline
\end{tabular}

Financial actors also differ in the skew of their portfolio. All utilities had a remarkably low entropy and thus strongly skewed portfolio; government agencies held by far the most balanced portfolio. State banks invested in the second-most balanced portfolio, closely followed by institutional investors and industrials, while commercial banks and energy companies and other state corporations had relatively skewed portfolios. These differences in skew are robust to the method of measurement; we have confirmed the ranking of portfolio skew using the Stirling (2007) diversity index, which gives a smaller balancing weight to spreading a portfolio over similar technologies. ${ }^{14}$ Although this perspective does not reveal the direction in which portfolios are skewed, the results clearly show that financial actors have a varying propensity to direct their investments to only subset of technologies.

Total portfolio skew is similar to the median financial actor skew and first rises then falls. This is not obvious, as very unbalanced financial actor portfolios can balance out when pooled (in the case of one investor financing only wind and the other only solar, their combined investment would be balanced). Thus, the direction created by individual investors is translated into overall direction. The Theil Index, with its opposite fluctuation, gives the additional insight that the while overall investment was most balanced during the crisis, the sum of investor skew was biggest in the crisis period; this suggests that financial actors steered toward fewer technologies, but that these preferred technologies differed between financial actors. However, despite an increase in the Theil Index post-crisis, the overall entropy was lowest in the most recent period, suggesting an increasing direction towards a

\footnotetext{
${ }^{14}$ Thus, different PV technologies are more similar to each other than PV and marine technologies for instance. See Stirling (2010b) for a dendrogram depicting RE technology similarities.
} 
Table 5

Share in total investment of each technology, entropy of its investor contributions, and total investment, total investor contribution entropy and technology-Theil Index for three periods. All figures except total investment expressed in percentages.

\begin{tabular}{|c|c|c|c|c|c|c|}
\hline \multirow[b]{2}{*}{ Financial actor } & \multicolumn{2}{|c|}{ 2004-2008 } & \multicolumn{2}{|c|}{ 2009-2011 } & \multicolumn{2}{|c|}{ 2012-2014 } \\
\hline & Share & Entropy & Share & Entropy & Share & Entropy \\
\hline Onshore & 47.7 & 87.6 & 48.0 & 87.4 & 46.1 & 89.1 \\
\hline Hydro & 7.1 & 58.9 & 2.9 & 85.5 & 1.2 & 83.1 \\
\hline Conv fuels & 17.2 & 74.7 & 4.0 & 73.4 & 1.1 & 71.7 \\
\hline Biomass & 13.0 & 82.2 & 9.1 & 87.4 & 5.5 & 91.5 \\
\hline c-Si PV & 8.3 & 82.9 & 16.5 & 90.9 & 31.9 & 88.6 \\
\hline Geothermal & 1.3 & 80.6 & 1.6 & 89.4 & 1.0 & 87.4 \\
\hline Other PV & 0.2 & 73.2 & 3.6 & 86.4 & 2.9 & 82.1 \\
\hline Adv fuels & 0.8 & 71.1 & 0.6 & 68.6 & 0.9 & 68.7 \\
\hline Offshore & 2.2 & 70.9 & 8.1 & 79.9 & 7.2 & 76.5 \\
\hline CSP & 1.9 & 63.6 & 5.6 & 80.0 & 2.3 & 85.7 \\
\hline Marine & 0.3 & 29.7 & 0.1 & 70.5 & 0.0 & 67.3 \\
\hline \multirow[t]{2}{*}{ Total } & USD & 89.5 & USD & 93.0 & USD & 92.7 \\
\hline & $379 b n$ & & $420 \mathrm{bn}$ & & $407 \mathrm{bn}$ & \\
\hline Theil Index & & 14.2 & & 13.3 & & 15.8 \\
\hline
\end{tabular}

subset of technologies, which we examine next.

\subsection{Consequences for technology finance}

The previous analysis showed that there is a different skew in investors' portfolios, but not toward which technology this skew directs. We conclude our analysis of size and skew differences by showing how the amount and composition of finance flowing to technologies differed as a consequence of the differences in financial actors' financing behavior.

Table 5 displays the same indices as Table 4 but for technologies that receive finance from a distribution of investors. The shares received by technologies are much more disparate than the shares contributed by different actors. Entropies are high compared to investor portfolios and, since they are normalized, are directly comparable with the latter. This suggests that most actors skewed their investment toward the same technology - onshore wind, and later on also c-Si PV giving these technologies a dominant share in the mix. Total entropy (of investor shares in total investment) was consistently higher than that in any individual entropy, showing that different financial actors did drive different directions that partially canceled each other out in the aggregate.

There is no clear trend over time of an increase or decrease in entropy. The Theil Index again shows that technologies received investment from a less diversified set of sources during than they did before or after the crisis. As for the evolution of shares over time, only two technologies - c-Si PV and advanced biofuels - increased their share from the crisis to the post-crisis period. This contributes to the new direction of finance not only toward onshore wind but also PV, which together received almost $80 \%$ of total finance in the most recent period.

To sum up the results in this section, financial actors differed in size and public actors became increasingly important, both as a group and individually. Types also differed in their portfolio composition, with some types investing in more directed portfolios than others. This was reflected in different technologies showing different sources of finance and an increasing share of finance received by only two technologies: onshore wind and c-Si PV. All of this confirms that financial actors differ in their tendency of creating technology directions both in how balanced their portfolios are and in which particular direction they go, if their portfolio is skewed.

\section{Differences in portfolio risk}

\subsection{Investor category risk}

While private finance has been greater in size, public finance has provided more high-risk finance. This is most easily seen by returning to the private and public investor categories. The left-hand panel of Fig. 5 depicts the risk exposure of public and private actors in every year. Private exposure to risk hovered consistently around $15 \%$, but peaked in 2009-2011, during the crisis. Meanwhile, public risk-taking fluctuated around a higher $20 \%$ in most years; therefore as public actors increased their share in investment, the overall share of high risk investment rose. Before interpreting the difference between more granular actors, we must investigate the crisis period further.

The special character of the crisis period, 2009-2011, was already observed in terms of portfolio size and skew. The Great Recession also saw large government stimuli, many of which went towards RE. In 2009, during the Great Recession, an additional USD 38 billion was committed by governments to boosting investment in RE, and much more went to other types of "clean technology" in the wake of national Keynesian stimulus packages (Robins et al., 2009). Most of these funds were spent during the 2009-2011 period. There was a large uptick in government share in the crisis period observed above, as well as a large increase in state bank finance, not captured in the deal-by-deal data (Louw, 2013). However, other measures boosted private investment appetite without public funds not reflecting in our asset finance data, for instance through grants and loan guarantee programs (Mundaca and Richter, 2015). Therefore, although we cannot analyze causality, it would be plausible to relate the higher risks taken by private finance between 2009 and 2011, at least in part to the contemporaneous government stimuli; further evidence for this is analyzed in Mazzucato and Semieniuk (2017).

Apart from the special crisis period, public risk-taking was consistently higher than private risk-taking in most years. This difference is made clearer by again excluding investments made in China in the right plot of Fig. 5. The private risk exposure is then slightly higher and similar in trend. However, the public risk exposure is entirely different without Chinese state-owned enterprises. From an initial level of around $30 \%$, public risk exposure followed a rising trend to almost $50 \%$.

Multiplying risk exposure by total finance, high risk investments were financed to three quarters by private actors until 2008, while almost half was financed by public actors in 2009. Subsequently the public share saw an increasing trend, to end at $56 \%$ of all high-risk deployment financed by public actors with and $58 \%$ without investments made in China in 2014. On average, publicly owned financial actors clearly had a greater "risk appetite" than privately owned ones and thus provided a direction towards financing high-risk projects.

\subsection{Financial actor risk}

We repeat the time series depiction of risk exposure at the level of financial actor risk exposure in Fig. 6, distributed over four plots: for (1) private non-financial and (2) financial actors, for (3) public non-financial actors and for (4) public banks and government. The entire plot shows that levels and trend of risk exposure were heterogeneous, with risk exposure ranging from $<10 \%$ to over $50 \%$. Looking more closely at private actors, all have relatively constant trendless risk exposure, interrupted by crisis period upward spikes. On average, financial organizations took on more risk in their investment portfolios, with the exception of industrials. The portfolio riskiness of financial actors was also more volatile, partly due to lumpy investments in high-risk CSP and offshore wind technologies. Although a number of small high-risk taking investment funds were included in the institutional investor bracket, banks invested in a riskier average portfolio than institutional investors. In the right panel, too, public banks have financed a riskier 


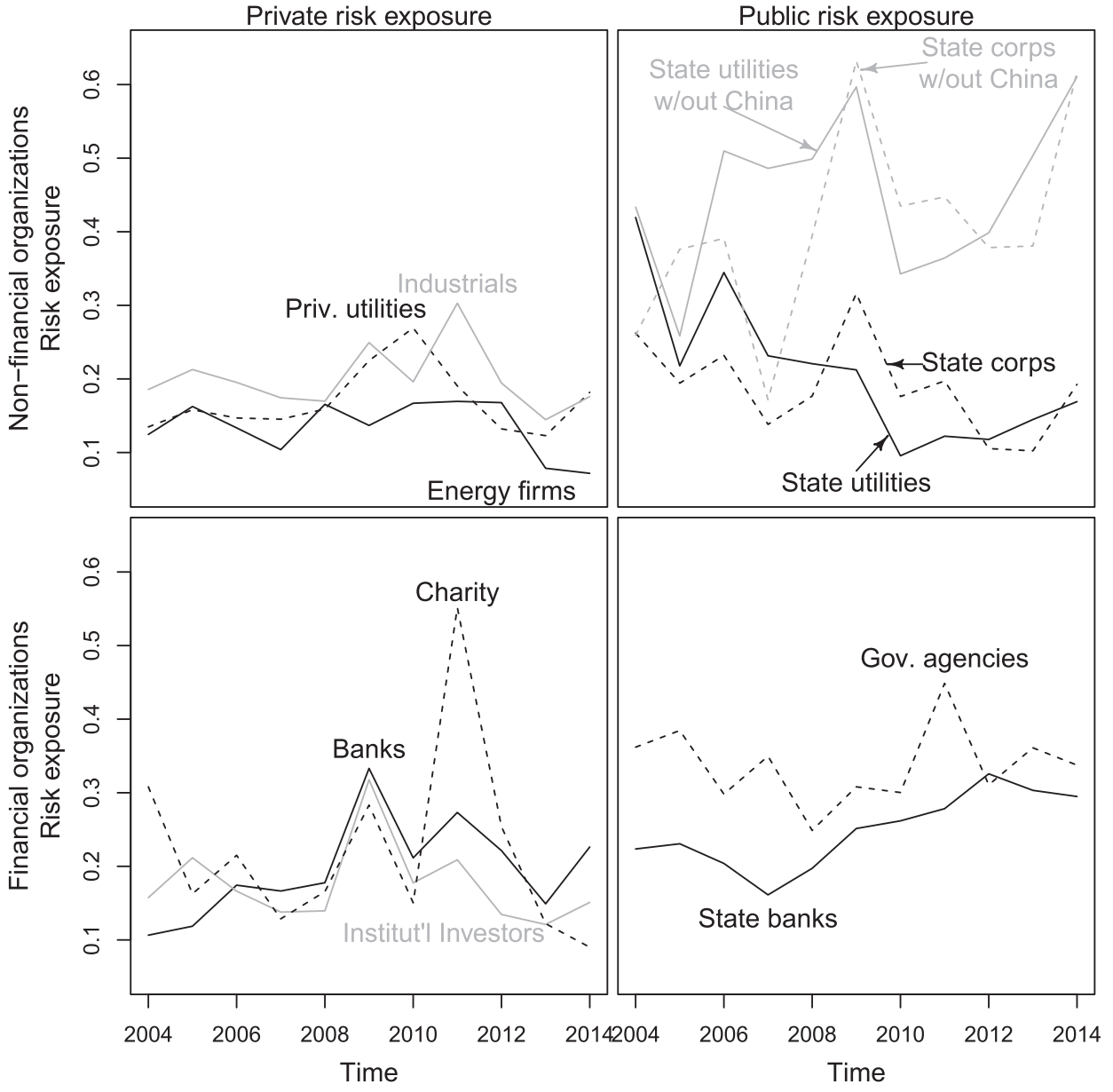

Fig. 6. Time series of financial actor portfolio risk exposure. portfolio than nonfinancial state-owned companies; however, removing investments in China by non-financial state-owned companies clearly shows that public non-financial institutions in the rest of the world invested into the highest risk portfolios. ${ }^{15}$ Moreover, their portfolio became more risk-taking over time, as did that of state banks.

Comparing the plots in the upper row reveals a sharp divide between private and non-Chinese public non-financial institutions. The former invest heavily in deploying low risk technologies and the latter invest strongly in high-risk assets. Public banks only became more risk taking than commercial banks by 2011 . Until then, the risk profile of commercial and state banks was similar (with the caveat that half of state bank investments are undisclosed and therefore cannot be assigned a risk index). Government agencies maintained a consistently high-risk profile; meanwhile, institutional investors, seen as the untapped reserve for future investment growth (OECD, 2015), had one of the least risk-taking profiles overall.

These results clearly show that financial actors build heterogeneous investments portfolios also in terms of risk exposure. Among private investors, commercial banks and industrials take on riskier investments, while state-owned non-financial corporations outside China are the most likely to take risks. The results confirm innovation theory in that public actors invest in high-risk finance; however, they also show that distinguishing financial actors at a more granular level than "public" and "private" may yield new insight into RE finance by associating a risk direction with particular financial actors. While the hypothesis that certain types of finance do not invest in high-risk deployment at all cannot be confirmed, it

\footnotetext{
${ }^{15}$ The series in the other panels barely change when investments in China are removed, locating the Chinese specificity in the size and skew towards low-risk onshore wind in their state-owned companies.
}

is clear that only a subset of financial actors are pushing back against a risk direction only to low risk investments. The remaining subsection explores four high-risk technologies in more detail to show the main financial actors that drove their expansion or decline.

\subsection{Contributions to high-risk technologies}

Underneath the risk-taking lies a direction towards certain RE technologies. The only four technologies that are high-risk throughout are offshore wind, CSP, marine, and advanced fuels. Looking at which financial actors set the direction toward them provides a more granular perspective on investor differences. Fig. 7 stacks time series of investment volumes for the three largest actors by cumulative finance and the sum of other investors in these technologies. The top-left plot shows that private and state utilities and state banks have, together, invested $>70 \%$ of cumulative investments into this sector, and an even higher percentage in the years before 2009. In CSP, the three largest financial actors - commercial banks, non-financial non-energy firms, and state banks - invest two-thirds of the total, and almost all of it before 2008; the major spike in 2010 is due mainly to government agencies' one-time investment. In marine technologies, where the total investment is almost two orders of magnitude lower, the dominance by a few investors is even more pronounced, with the top three - state utilities, government, and energy firms - providing $80 \%$ of all funds. The share of $80 \%$ is also achieved by the three top investors into advanced fuels: energy firms, non-energy non-financial firms, and state banks.

Another way to analyze this is to consider contributions to growth of the investment. Table 6 shows that the top financial actors also drive the change in investment over time, with more than half of growth or decline in investment attributable to single investors. The table also 

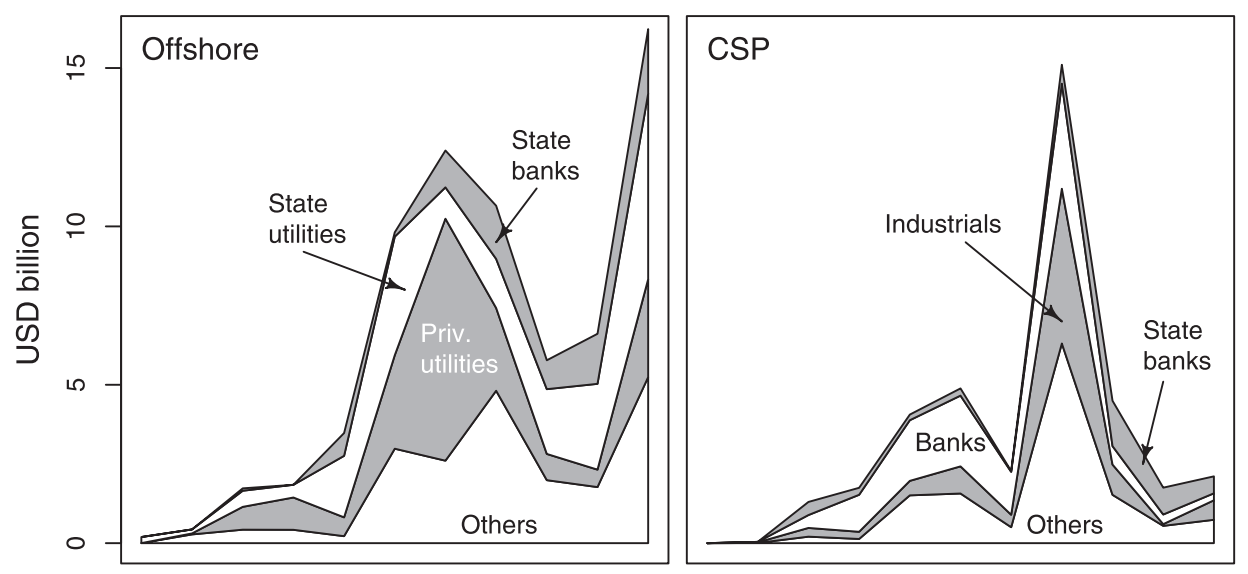

Fig. 7. Stacked volumes of annual investments by top three investors in four high-risk technologies; the lower plots have a y-axis scale an order of magnitude smaller.
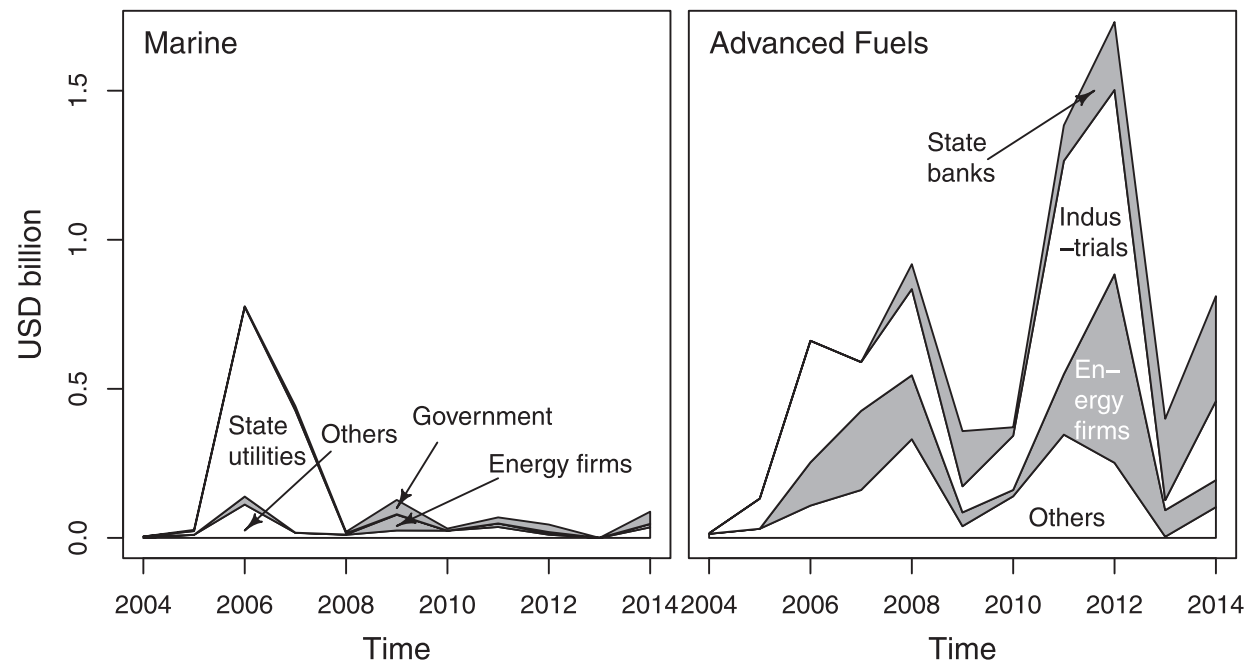

Table 6

Contributions to growth in crisis period (CG 1) and in post-crisis period (CG 2) of investment into four high-risk technologies of the top three financial actors of other financial actors and total technology investment growth rate. All figures in percentages.

\begin{tabular}{llllll}
\hline Financial actor & CG 1 & CG 2 & Financial actor & CG 1 & CG 2 \\
\hline Offshore & & & CSP & & \\
Priv. utilities & 129.6 & -25.8 & Industrials & 72.1 & -19.3 \\
State banks & 26.1 & 4.6 & Banks & 47.6 & -24.8 \\
State utilities & 37.3 & 12.8 & State banks & 0.5 & 8.4 \\
Others & 111.5 & -5.4 & Others & 106.2 & -24.8 \\
Total & 304.5 & -13.9 & Total & 226.4 & -60.6 \\
Marine & & & Advanced fuels & & \\
Energy firms & 2.5 & 0.1 & Energy firms & -11.4 & 20.0 \\
State utilities & -83.3 & -4.4 & Industrials & 0.7 & -2.5 \\
Gov. agencies & 3.9 & 0.8 & State banks & 8.0 & 19.2 \\
Others & -1.8 & -0.8 & Others & -10.0 & -2.8 \\
Total & -78.7 & -4.3 & Total & -12.7 & 33.9 \\
\hline
\end{tabular}

shows that investors can have contradictory dynamics in their portfolios. Thus, state banks and state utilities grow their investments in offshore and CSP in the post-crisis period, but their increase is more than counterbalanced by the decline in investments of all other types. In the case of marine, the decline in investment by state-owned utilities is stronger than the growth by all other actors. In advanced fuels, growing investments by energy firms and state banks overwhelm the declining trend in other financial actors.

These results reinforce the low entropy results for the high-risk technologies in Table 5 and illustrate that the amount of finance a particular high-risk technology receives depends largely on only a few financial actors; so does the cumulative investment and the experience and ability to bring down costs. Moreover, most financial actors are only strongly active in one or two high-risk technologies; hence, they are pushing particular directions within RE, with the most notable exception being state banks. The less risky technologies (except hydro) display a much more balanced distribution of financial actors, and total investment volume also varies more strongly over time for high-risk technologies than for low-risk ones. On one hand, it is not surprising that higher-risk, lower-volume technologies have fewer investment types and more volatility in their investment amount. However, it is also important to highlight that which actor type allocates finance to particular technologies matters most during the highrisk deployment stage for setting directions, and that some financial actors are more active in setting this direction than others (we counted state banks in three technologies and energy companies, industrials, and state utilities twice).

\section{Conclusion and policy implications}

In this paper, we have used BNEF asset finance data between 2004 and 2014 and a heuristic risk measure to study heterogeneity in financial actors in the RE sector. We have analyzed differences in size, skew, and risk exposure of the portfolios that financial actors invested in; we have also considered how technologies differ in the amount and composition of finance they receive. We have found that different financial actors contribute to varying technology directions: some have balanced portfolios, while others have strongly directed ones toward particular technologies, where particular actors may have a disproportionate influence on a particular technology's deployment. Actors also differ in their risk direction towards high or low-risk technologies, with private ones favoring low risk much more than public ones, and individual high risk technologies pushed mainly by just two or three financial actors. Public actors have also 
accounted for an increasing share in overall investment. We have argued that it is important to understand the directionality of innovation as this can affect the success of innovation and resilience of the RE energy system, so that options remain open in case innovation in a narrow set of technologies stalls.

While our results must take into consideration the gaps in the data and the heuristic nature of the risk index, the patterns suggest that emphasis should move from the total amount of finance to its composition by financial actors and areas of investment. We now discuss four high-level implications for policy and sketch the need for further research.

First, our results suggest that it is important to understand the consequences of different types of financial investments for the direction of RE innovation. If policies favor a subset of financial actors, these actors will come with their particular priorities of financing. Examples of such actor-specific policies include attempts to incentivize institutional investors to invest more in the RE sector (OECD, 2015), the creation of 'funds of funds', and the creation of new actors such as a state bank or the privatization of utilities. Understanding the historical directions these actors have created may help explain the impact such policies will have on a national technology mix.

Second, and conversely, the design of technology-specific policies benefits from gathering knowledge about the heterogeneity in financial actors. An awareness of the historical trend of which types of finance have invested in that technology may help create incentives for that type of finance. For instance, if there is a preference for concentrating solar power plants, it may be useful to know that, since the financial crisis, these have mainly been financed by state banks, industrial firms, and government agencies. Creating funds of funds in this case may not change much. These considerations become particularly salient for new, high risk technologies, and may be important for other sectors, too.

Third, more attention needs to be given to the coordination of different types of financing in the deployment phase. Policy makers tend to focus only on a "market failure" justification of public policy. In the case of RE this has resulted in the correction of market failures in the upstream (R \& D) phase through public agencies, and the use of VC for the product development phase (VC), but equal emphasis should be placed on the deployment phase. Yet, to coordinate policies this might require a market shaping and market creating strategy that goes beyond the market fixing framework (Mazzucato, 2016a). The use of "missionoriented" policies (Foray et al., 2012) to both catalyze a new sector and to ensure the new technologies are fully diffused and deployed, as happened with the IT revolution, could be useful for the green tech sector (see also Mazzucato and Semieniuk, 2017).

Fourth, these results show more generally that the type of financial actor matters, and at a more finely grained level than just "private" vs. "public". Awareness that finance can create directions - whether planned by policy makers or not - is an important point to heed when designing policies. To map the effects that policies have on the direction and not just the amount of financial funds before implementing policies, will help prevent surprises and lock-ins later. Mazzucato and Semieniuk (forthcoming) discuss the importance of public financing in shifting investment in the energy sector towards the direction of clean technologies.

Our results are preliminary and future research might extend this work in several dimensions. One important theoretical question is why financial actors have different investment risk profiles, and how this translates into particular types of portfolio choices which go beyond the risk analysis of portfolio theory (Merton, 1969; Ross, 1976). Private actors may behave differently if motivated in their investment choice by the perception of future profitability in areas, especially based on the evidence that what matters is not current profits but expectations about future growth (Dosi and Lovallo, 1997). Or put another way, business' animal spirits are endogenous to public investment (Dow and Dow, 2012; Mazzucato, 2016a). It is important to understand how public policies or investment choices affect these perceptions.

Another question is how public and private investments interact and whether the ability of public investment to leverage private investment differs for different types of public financial institutions. This can provide insights into different types of crowding-in processes, that are being assumed for example in the Juncker plan for investment-led growth (European Commission, 2014) and how they differ across technologies and/or periods in the technology life-cycles. Tying these results to directions may enable developing more precise policy advice on how directions in RE innovation are being and can be influenced by the decisions of financial actors. One obstacle to a more precise quantitative analysis of financial actors' roles is the large amount of missing data on investor participations as opposed to deal values. A Bayesian missing data analysis may go some way to improving our understanding of "who is doing what" quantitatively. Ultimately, however, better data reporting and collection will have to be implemented alongside more narrowly focused research.

\section{Appendix A. Dataset construction}

We constructed the dataset by first merging three databases that list equity, lead and syndicated debt finance for asset finance deals (BNEF, 2015b). We created the value of each investor's participation in an asset finance deal by splitting deal values between equity and debt and allocating the share of the value to the participating investors. The raw BNEF asset databases record deal value, debt value, and investor shares, but a portion of the data are missing. Although $55.8 \%$ of deal values are missing, BNEF imputes a deal value to each project. $77.2 \%$ of participant shares are missing and BNEF does not impute them. In order to attribute a share to every disclosed investor anyway we first reduced missingness to $23 \%$, by assuming that whenever only a single equity sponsor without debt is disclosed, this deal is entirely financed by this sponsor (the problems this creates for underrepresenting undisclosed debt are discussed in the main text). Second, where more than one sponsor/creditor is disclosed and share values are missing, we distributed the unknown shares of each deal's equity equally between sponsors while assuming, whenever creditors are disclosed, that the share of debt in the deal is equal to the average share of debt in the disclosed data, with a gearing ratio of $66 \%$. We then imputed debt shares by distributing the imputed debt value equally over creditors. ${ }^{16}$ With all missingness removed, the date of deal closure identified the time of asset finance, and closure dates were coarse-grained into annual or multi-annual intervals. Finally, we trimmed the dataset of all investments in the "refinancing" and "acquisition" categories to only count newly added capacity.

Next, in order to create financial actors, we merged our asset dataset with the database classifying investors. The latter distinguishes investors according to their ownership structure and their industrial classification. Ownership structure distinguishes between publicly listed and privately owned companies, non-profit institutions, government agencies, etc. The Bloomberg industry classification system is similar to the Global Industrial Classification System (GICS), which has 10 sectors, 24 industry groups, and is further subdivided at the "industry" and "sub-industry" levels. We then used ownership structure to identify privately or publicly owned organizations. Within public ownership we further distinguished "government

\footnotetext{
${ }^{16}$ Equal share imputation may misrepresent single investors' contributions. An example is the Gemini Offshore Wind Farm debt financing from 17 actors, for which BNEF does not

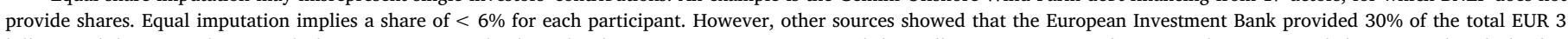

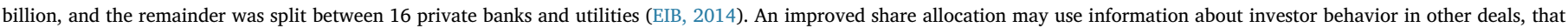
could be implemented in a Bayesian missing data analysis.
} 
agencies" from corporations, and within private ownership we distinguished for profit from not for profit organizations. Finally we used the GICS sectors "energy", "utilities", "finance" and all other sectors, and within the finance sector, the industry groups "Banks" and all other industry groups, to create financial actors within public and private categories that distinguish organizations according to their function, while grouping as many different forms and industries as possible to reduce complexity.

\section{Appendix B. Risk measure construction}

\section{B.1. Technology and market risk}

We used studies of technology risk and time series of LCOE estimates for market risk to assign a risk indicator to each of eleven technologies for each year from 2004 to 2014. Existing comparative classifications of either technology or market risk for RE are scarce. We started with the exception in Szabó et al. (2010), who estimate both technology and market risk for 6 technologies as low, medium or high and added the remaining technologies from the more comprehensive (Altran, 2011) study by comparing their riskiness with those given by Szabo et al. and assigning them the same low medium or high risk class. We then used level and changes in component prices and levelized cost of energy (LCOE) data from BNEF (2014b, 2015a), the Fraunhofer Institute (2013) and the World Energy Council (Salvatore, 2013), and for earlier years up to 2009 and 2010 from the IPCC special report on RE (Mitchell et al., 2011), as well as additional information about technological maturity (detailed below), to extend the 2009 risk classification backward and forward to every year between 2004 and 2014 . We distinguished sub-technologies where there were significant risk differences within one of our 11 technologies, such as between thin-film PV and concentrator PV.

The resulting classification in Table 3 in the main text is created as follows. Onshore wind financing was low risk in all years, with significant capacity already installed in 2004, and prices often competitive with fossil energy source (Salvatore, 2013). Offshore wind was a high-risk investment throughout; until 2014, it continued to experience technical setbacks and difficulties, such as connecting power plants to the grid (KfW, 2014, 2015, p. 77 \& 100), and the oldest large-scale offshore wind farms have not yet reached the end of their estimated lifetime (Ho et al., 2016). Meanwhile, levelized costs remain significantly above those for onshore and fossil-fuel-generated power (BNEF, 2015a).

In the solar sector, c-Si PV's component price fell by almost $90 \%$ over the 11 dataset years, leading Szabo et al. to classify c-si PV as low risk as early as 2009. The thin-film PV alternatives dropped to medium risk in 2010, with a similar cost structure, but less information about technological performance. Only concentrator PV remains high-risk throughout, as this technology is only now transcending the pilot stage and costs remain high relative to other PV technologies (Phillips et al., 2015). Concentrating solar power (CSP) is high-risk in every year. The high level of LCOE hardly decreased between 2006 and 2012 in most region (Stadelmann et al., 2014). A surge in US installations in 2011 was driven by public grants, and private loans underwritten by public loan guarantees, because the risk was too high for other types of finance (Mendelsohn and Kreycik, 2012). Moreover, technology designs are still in major flux (European Commission, 2013).

We divided biofuels into first- and second-generation fuels, where the latter were high-risk and the former (fermentation of edible plants into ethanol, and transesterification for biodiesel) low-risk, following the usual classification in the literature (Schwaiger et al., 2011; Sims et al., 2010). Biomass was split into low and medium risk in order to distinguish the widespread use of incineration plants from those using other, less experienced technologies (Balat, 2009). Marine energy was high-risk throughout, as these technologies remained in the pilot stage in 2014, and levelized cost far exceeded that of any other technology in the sample (BNEF, 2015a). Geothermal technologies were medium risk investments. There is a long history of building commercially viable geothermal power plants (Fridleifsson, 2003), but the need to commit large amounts of capital early on and build site-specific power plants kept individual investments risky (BNEF, 2014b). Small hydro was low-risk in all years, as it is a well-tested technology (Mitchell et al., 2011) and its LCOE tended to be among the lowest of all technologies (BNEF, 2015a).

\section{B.2. Country risk}

The Renewable Energy Country Attractiveness Index (RECAI) is compiled by Ernst and Young (2015) and ranks countries in every quarter for the entire dataset period according to their investment climate, political stability, ability to connect power plants to the grid, priority of RE over other low-carbon energy forms, electricity prices, and RE support policies for various RE, all of which are weighted according to the importance of different RE technologies in the electricity mix. Country scores vary between 25 (worst) and 75 (best). The RECAI started with 17 countries in 2004 and ranked 40 countries by 2012. In order to translate the RECAI into a country risk factor that is additive to the above risk index, we centered the RECAI around zero and scaled it so that the maximal deviation from zero is the modulus of $\frac{1}{6}$ and is inversely proportional to the score. This makes a high RECAI country score translate into a low country risk factor, which reduces the risk of an investment in this country. Countries that do not appear in the RECAI account for only $3 \%$ of total investments; we assigned them a country risk indicator of $+\frac{1}{6}$. Fig. 8 shows a sample of country risk factor time series.

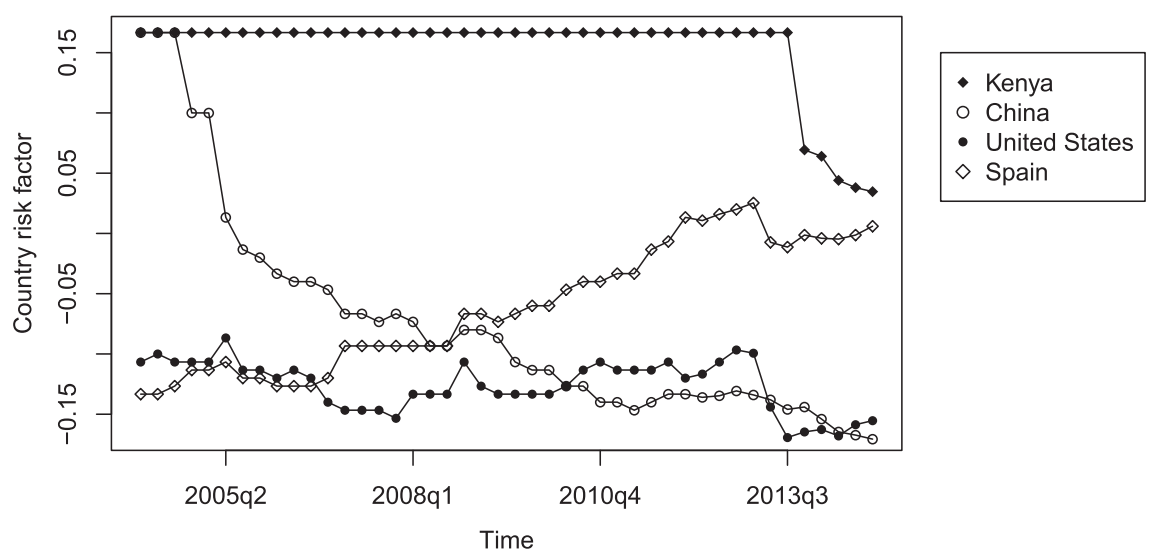

Fig. 8. Country risk factor calculated from RECAI ranking for selected countries. 


\section{References}

Abbate, J., 1999. Inventing the Internet. MIT Press, Cambridge, MA.

Acemoglu, D., Akcigit, U., Hanley, D., Kerr, W., 2016. Transition to clean technology. J. Polit. Econ. 124 (1), 52-104. http://dx.doi.org/10.1086/684511.

Altran, 2011. Risk Quantification and Risk Management in Renewable Energy Projects. Altran GmbH \& Co.(http://iea-retd.org/wp-content/uploads/2011/11/RISK-IEARETD-2011-6.pdf).

Arrow, K.J., 1962. The economic implications of learning by doing. Rev. Econ. Stud. 29 (3), 155-173. http://dx.doi.org/10.2307/2295952.

Arthur, W.B., 1989. Competing technologies, increasing returns, and lock-in by historical events. Econ. J. 99 (394), 116-117. http://dx.doi.org/10.2307/2234208.

Auerswald, P.E., Branscomb, L.M., 2003. Valleys of death and Darwinian seas: financing the invention to innovation transition in the United States. J. Technol. Transfer. 28, 227-239.

Balat, M., 2009. Global status of biomass energy use. Energy Sources A 31 (13), $1160-1173$.

Bera, A.K., Park, S.Y., 2008. Optimal portfolio diversification using the maximum entropy principle. Econ. Rev. 27 (4-6), 484-512. http://dx.doi.org/10.1080/ 07474930801960394.

Bergek, A., Mignon, I., Sundberg, G., 2013. Who invests in renewable electricity production? Empirical evidence and suggestions for further research. Energy Policy 56 (C), 568-581. http://dx.doi.org/10.1016/j.enpol.2013.01.038.

BNEF, 2014a. State Bank Finance Database. Bloomberg New Energy Finance.

BNEF, 2014b. Sustainable Energy in America Factbook. Bloomberg New Energy Finance.

BNEF, 2015a. 2015 Factbook: Sustainable Energy in America. Bloomberg New Energy Finance.

BNEF, 2015b. Asset Finance Database. Bloomberg New Energy Finance.

BNEF, 2015c. R \& D Database. Bloomberg New Energy Finance.

Buchner, B.K., Trabacchi, C., Mazza, F., Abramskiehn, D., Wang, D., 2015. Global Landscape of Climate Finance 2015. Climate Policy Initiative.

Cárdenas Rodríguez, M., Haččič, I., Johnstone, N., Silva, J., Ferey, A., 2014. Inducing private finance for renewable energy projects: evidence from micro-data. In: OECD Environment Working Paper No. 67, http://dx.doi.org/10.1787/5jxvg0k6thr1-en.

Criscuolo, C., Menon, C., 2015. Environmental policies and risk finance in the green sector: cross-country evidence. Energy Policy 83, 38-56.

Criscuolo, C., Johnstone, N., Menon, C., Shestalova, V., 2014. Renewable energy policies and cross-border investment: evidence from mergers and acquisitions in solar and wind energy. In: OECD Science, Technology and Industry Working Paper No. 2014/ 03, http://dx.doi.org/10.1787/5jxv9f3r9623-en.

Dangerman, A.T.C.J., Schellnhuber, H.J., 2013. Energy systems transformation. Proc Natl. Acad. Sci. 110 (7), E549-E558. http://dx.doi.org/10.1073/pnas.1219791110.

David, P.A., 1985. Clio and the economics of QWERTY. Am. Econ. Rev. 75 (2), 332-337.

Denton, M., Palmer, A., Masiello, R., Skantze, P., 2003. Managing market risk in energy. IEEE Trans. Power Syst. 18 (2), 494-502. http://dx.doi.org/10.1109/TPWRS.2003. 810681.

Dosi, G., Lovallo, D., 1997. Rational entrepreneurs or optimistic martyrs? Some considerations on technological regimes, corporate entries, and the evolutionary role of decision biases. In: Garud, R., Nayyar, P.R., Shapira, Zur Baruch (Eds.), Technological Innovation Oversights and Foresights. Cambridge University Press, Cambridge, UK.

Dow, S.C., Dow, A., 2012. Animal spirits and rationality. In: Dow, S.C. (Ed.), Foundations for New Economic Thinking: A Collection of Essays. Palgrave Macmillan UK, London. http://dx.doi.org/10.1057/9781137000729_3.

EDF, 2016. Reference Document: 2015 Annual Financial Report. EDF Group.

EIB, 2014. Dutch Renewable Energy Boosted by EUR 587m EIB Backing for World's Largest Wind Farm. European Investment Bank(Retrieved April 6, 2016, from http:// www.eib.org/infocentre/press/releases/all/2014/2014-107-dutch-renewableenergy-boosted-by-eur-587m-eib-backing-for-worlds-largest-wind-farm.htm).

Ernst \& Young, 2015. Renewable Energy Country Attractiveness Index, No. 43.

European Commission, 2013. Technology assessment. In: Commission Staff Working Document No. SWD(2013) 158 final.

European Commission, 2014. An investment plan for Europe. In: COM/2014/0903 Final.

Eyraud, L., Clements, B., Wane, A., 2013. Green investment: trends and determinants. Energy Policy 60 (C), 852-865. http://dx.doi.org/10.1016/j.enpol.2013.04.039.

Fischhoff, B., Watson, S.R., Hope, C., 1984. Defining risk. Policy Sci. 17 (2), 123-139. http://dx.doi.org/10.1007/BF00146924.

Foray, D., Mowery, D.C., Nelson, R.R., 2012. Public R \& D and social challenges: what lessons from mission R \& D programs? Res. Policy 41 (10), 1697-1702. http://dx.doi. org/10.1016/j.respol.2012.07.011.

Fraunhofer Institute, 2013. Levelised Cost of Renewable Electricity Renewable Energy Technologies. Fraunhofer Institute Study.

Fridleifsson, I.B., 2003. Status of geothermal energy amongst the world's energy sources. Geothermics 32 (4-6), 379-388,

Gaddy, B., Sivaram, V., OSullivan, F., 2016. Venture Capital and Cleantech: the wrong model for clean energy innovation. In: MITEI-Working Paper No. 2016-06.

Ghosh, S., Nanda, R., 2010. Venture capital investment in the clean energy sector. In: Harvard Business School Working Paper No. 11-020.

Griffith-Jones, S., Cozzi, G., 2016. Investment-led growth: a solution to the European crisis. In: Jacobs, M., Mazzucato, M. (Eds.), Rethinking Capitalism. Wiley Blackwell.

Grubb, M., 2014. Planetary Economics. Routledge, Oxford and New York.

Grubler, A., 2012. Energy transitions research: insights and cautionary tales. Energy Policy 50 (C), 8-16.

Hall, B.H., 2002. The financing of research and development. Oxf. Rev. Econ. Policy 18 (1), 35-51. http://dx.doi.org/10.1093/oxrep/18.1.35.
Hall, B.H., Lerner, J., 2009. The financing of R \& D and innovation. In: NBER Working Paper No. 15325 .

Hartmann, G.C., Lakatos, A.I., 1998. Assessing technology risk-a case study. Res. Technol. Manag. 41 (2), 32-38.

Hartmann, G.C., Myers, M.B., 2001. Technical risk, product specifications, and market risk. In: Branscomb, L.M., Auerswald, P.E. (Eds.), Taking Technical Risks: How Innovators, Executives and Investors Manage High-Tech Risks. MIT Press, Cambridge, MA and London.

Haščič, I., Cárdenas Rodríguez, M., Jachnik, R., Silva, J., Johnstone, N., 2015. Public interventions and private climate finance flows: empirical evidence from renewable energy financing. In: OECD Environment Working Paper No. 80, http://dx.doi.org/ 10.1787/5js6b1r9lfd4-en.

Ho, A., Mbistrova, A., Corbetta, G., 2016. The European Offshore Wind Industry - Key Trends and Statistics 2015. European Wind Energy Association.

International Energy Agency, 2014. World Energy Investment Outlook 2014 Special Report. International Energy Agency.

International Energy Agency, 2015. Medium-Term Renewable Energy Market Report 2015. International Energy Agency.

Jaffe, A.B., Newell, R.G., Stavins, R.N., 2005. A tale of two market failures: technology and environmental policy. Ecol. Econ. 54 (2-3), 164-174. http://dx.doi.org/10. 1016/j.ecolecon.2004.12.027.

Johnstone, N., Haščič, I., Popp, D., 2009. Renewable energy policies and technological innovation: evidence based on patent counts. Environ. Resour. Econ. 45 (1), 133-155. http://dx.doi.org/10.1007/s10640-009-9309-1.

Kalamova, M., Kaminker, C., Johnstone, N., 2011. Sources of finance, investment policies and plant entry in the renewable energy sector. In: OECD Environment Working Paper No. 37, http://dx.doi.org/10.1787/5kg7068011hb-en.

Keller, M.R., Block, F., 2013. Explaining the transformation in the US innovation system: the impact of a small government program. Soc. Econ. Rev. 11 (4), 629-656. http:/ dx.doi.org/10.1093/ser/mws021.

Kerr, W.R., Nanda, R., 2015. Financing innovation. Annu. Rev. Financ. Econ. 7 (1), 445-462. http://dx.doi.org/10.1146/annurev-financial-111914-041825.

KfW, 2014. Annual Report 2013. Kreditanstalt für Wiederaufbau.

KfW, 2015. Annual Report 2014. Kreditanstalt für Wiederaufbau.

Langniss, O., 1996. Instruments to foster renewable energy investments in Europe: a survey under the financial point of view. Renew. Energy 9 (1-4), 1112-1115. http:// dx.doi.org/10.1016/0960-1481(96)88473-4.

Lazonick, W., Tulum, Ö., 2011. US biopharmaceutical finance and the sustainability of the biotech business model. Res. Policy 40 (9), 1170-1187. http://dx.doi.org/10. 1016/j.respol.2011.05.021.

Lerner, J., 2012. The narrowing ambitions of venture capital. MIT Technol. Rev. 115 (6), 76-78.

Louw, A., 2013. Development Banks - Breaking the \$100bn-a-year Barrier. Bloomberg New Energy Finance.

MacKenzie, C.A., 2014. Summarizing risk using risk measures and risk indices. Risk Anal. 34, 2143-2162. http://dx.doi.org/10.1111/risa.12220.

Masini, A., Menichetti, E., 2012. The impact of behavioural factors in the renewable energy investment decision making process: conceptual framework and empirical findings. Energy Policy 40 (C), 28-38. http://dx.doi.org/10.1016/j.enpol.2010.06. 062.

Markowitz, H., 1952. Portfolio Selection. J. Financ. 7 (1), 77-91.

Masini, A., Menichetti, E., 2013. Investment decisions in the renewable energy sector: an analysis of non-financial drivers. Technol. Forecast. Soc. Chang. 80 (3), 510-524. http://dx.doi.org/10.1016/j.techfore.2012.08.003.

Mazzucato, M., 2013. The Entrepreneurial State. Anthem Press, London and New York.

Mazzucato, M., 2016a. From market fixing to market-creating: a new framework for innovation policy. Ind. Innov. 23 (2), 140-156. http://dx.doi.org/10.1080/13662716. 2016.1146124.

Mazzucato, M., 2016b. Innovation, the state and patient capital. In: Jacobs, M., Mazzucato, M. (Eds.), Rethinking Capitalism. Wiley Blackwell, Chichester.

Mazzucato, M., Penna, C.C.R., 2016. Beyond market failures: the market creating and shaping roles of state investment banks. J. Econ. Policy Reform 19 (4), 305-326. http://dx.doi.org/10.1080/17487870.2016.1216416.

Mazzucato, M., Semieniuk, G., 2017. Public financing of innovation: new questions. Oxf. Rev. Econ. Policy 33 (1), 22-48.

Mazzucato, M. and Semieniuk, G., Financing Green Growth, In: Fouquet, R., (Ed.) Handbook on Green Growth, forthcoming, Elgar; Cheltenham.

Mazzucato, M., Wray, R.L., 2015. Financing the capital development of the economy: a Keynes-Schumpeter-Minsky synthesis. In: Levy Institute Working Paper No. 837.

Mendelsohn, M., Kreycik, C., 2012. Federal and state structures to support financing utility-scale solar projects and the business models designed to utilize them. In: NREI Technical Report No. NREL/TP-6A20-48685, (www.nrel.gov/docs/fy12osti/48685. pdf).

Merton, R.C., 1969. Lifetime portfolio selection under uncertainty: the continuous-time case. Rev. Econ. Stat. 51 (3), 247-257.

Mitchell, C., Sawin, J.L., Pokharel, G.R., Kammen, D., Wang, Z., Fifita, S., et al., 2011. Policy, financing and implementation. In: Edenhofer, O., Pichs-Madruga, R., Sokona, Y., Seyboth, K., Matschoss, P., Kadner, S. (Eds.), IPCC Special Report on Renewable Energy Sources and Climate Change Mitigation. Cambridge University Press, Cambridge UK, and New York.

Modigliani, F., Miller, M.H., 1959. The cost of capital, corporation finance, and the theory of investment: reply. Am. Econ. Rev. 49 (4), 655-669.

Mundaca, L., Richter, J.L., 2015. Assessing "green energy economy" stimulus packages: evidence from the U.S. programs targeting renewable energy. Renew. Sust. Energ. Rev. 42 (C), 1174-1186. http://dx.doi.org/10.1016/j.rser.2014.10.060. 
OECD, 2015. Mapping Channels to Mobilise Institutional Investment in Sustainable Energy. Green Finance and Investment, OECD Publishing, Paris. http://dx.doi.org/ 10.1787/9789264224582-en.

Owen, G., Hopkins, M.M., 2016. Science, the State and the City: Britain's Struggle to Succeed in Biotechnology. Oxford University Press, Oxford.

Phillips, S.P., Bett, A.W., Horowitz, K., Kurz, S., 2015. Current Status of Concentrator Photovoltaic (CPV) Technology. Version 1.1. Fraunhofer ISE and NREL(http://www. nrel.gov/docs/fy16osti/65130.pdf).

Pisano, G.P., 2006. Science Business: The Promise, the Reality and the Future of Biotech. Harvard Business School Press, Boston.

Polzin, F., Migendt, M., Täube, F.A., von Flotow, P., 2015. Public policy influence on renewable energy investments-a panel data study across OECD countries. Energy Policy 80 (C), 98-111. http://dx.doi.org/10.1016/j.enpol.2015.01.026.

Popp, D., 2011. Innovation and climate policy. In: NBER Working Paper No. 15673.

Popp, D., Haščič, I., Medhi, N., 2011. Technology and the diffusion of renewable energy. Energy Econ. 33 (4), 648-662. http://dx.doi.org/10.1016/j.eneco.2010.08.007.

Robins, N., Clover, R., Singh, C., 2009. A Climate for Recovery. HSBC Global Resarch.

Ross, S.A., 1976. The arbitrage theory of capital asset pricing. J. Econ. Theory 13 (3), 341-360.

Sagar, A.D., van der Zwaan, B., 2006. Technological innovation in the energy sector: R \& D, deployment, and learning-by-doing. Energy Policy 34 (17), 2601-2608. http://dx.doi.org/10.1016/j.enpol.2005.04.012.

Salvatore, J., 2013. World Energy Perspective. World Energy Council(https://www. worldenergy.org/wp-content/uploads/2013/09/WEC_J1143 CostofTECHNOLOGIES 021013 WEB Final.pdf).

Schapiro, M., 2012. Rediscovering the developmental path? Development bank, law, and innovation financing in the Brazilian economy. SSRN Electron. J. http://dx.doi.org/ $10.2139 /$ ssrn. 1986915.

Schumpeter, J.A., 1939. Business Cycles. Vol. 1 McGraw-Hill, New York and London.

Schwaiger, H., Pena, N., Mayer, A., Bird, D.N., 2011. Technologies to produce liquid biofuels for transportation: an overview. In: Center for International Forestry Research (CIFOR) Working Paper 72, http://dx.doi.org/10.17528/cifor/003510.

Shannon, C., 1948. A mathematical theory of communication. Bell Syst. Tech. J. 27 (3), 379-423.

Shimada, G., 2017. Inside the black box of Japan's institution for industrial policy: an institutional analysis of the development bank, private sector, and labor. In: Noman, A., Stiglitz, J.E. (Eds.), Efficiency, Finance and Varieties of Industrial Policy. Columbia University Press, New York.

Sims, R.E.H., Mabee, W., Saddler, J.N., Taylor, M., 2010. An overview of second generation biofuel technologies. Bioresour. Technol. 101 (6), 1570-1580. http://dx.doi. org/10.1016/j.biortech.2009.11.046.

Stadelmann, M., et al., 2014. The Role of Public Finance in CSP: Background and Approach to Measure Its Effectiveness. Climate Policy Initiative: San Giorgio Group Brief.

Stern, N., 2015. Why Are We Waiting?: The Logic, Urgency, and Promise of Tackling Climate Change. MIT Press.

Stirling, A., 2007. A general framework for analysing diversity in science, technology and society. J. R. Soc. Interface 4 (15), 707-719. http://dx.doi.org/10.1098/rsif.2007 0213.

Stirling, A., 2010a. Keep it complex. Nature 468, 1029-1031.

Stirling, A., 2010b. Multicriteria diversity analysis: a novel heuristic framework for appraising energy portfolios. Energy Policy 38 (4), 1622-1634. http://dx.doi.org/10 1016/j.enpol.2009.02.023.

Stirling, A., 2011. Pluralising progress: from integrative transitions to transformative diversity. Environ. Innov. Soc. Transit. 1 (1), 82-88. http://dx.doi.org/10.1016/j. eist.2011.03.005.

Stirling, A., 2014. Transforming power: social science and the politics of energy choices Energy Res. Soc. Sci. 1, 83-95. http://dx.doi.org/10.1016/j.erss.2014.02.001.

Szabó, S., Jäger-Waldau, A., Szabó, L., 2010. Risk adjusted financial costs of photovoltaics. Energy Policy 38 (7), 3807-3819. http://dx.doi.org/10.1016/j.enpol.2010. 03.001 .

Theil, H., Finizza, A.J., 1971. A note on the measurement of racial integration of schools by means of informational concepts. J. Math. Sociol. 1 (2), 187-193. http://dx.doi. org/10.1080/0022250X.1971.9989795.

Tietjen, O., Pahle, M., Fuss, S., 2016. Investment risks in power generation: a comparison of fossil fuel and renewable energy dominated markets. Energy Econ. 58 (C), $174-185$.

UNEP \& BNEF, 2015. Global Trends in Renewable Energy Investment 2015. Frankfurt School of Finance \& Management.

Veugelers, R., 2012. Which policy instruments to induce clean innovating? Res. Policy 41 (10), 1770-1778. http://dx.doi.org/10.1016/j.respol.2012.06.012.

Wüstenhagen, R., Menichetti, E., 2012. Strategic choices for renewable energy investment: conceptual framework and opportunities for further research. Energy Policy 40 (C), 1-10. http://dx.doi.org/10.1016/j.enpol.2011.06.050.

Zindler, E., Locklin, K., 2010. Crossing the Valley of Death. Bloomberg New Energy Finance.

Mariana Mazzucato is Professor in the Economics of Innovation \& Public Value, University College London (UCL) and Director of UCL's new Institute for Innovation and Public Purpose. She is author of the highly-acclaimed book The Entrepreneurial State: debunking public vs. private sector myths (Anthem, 2013; Public Affairs, 2015) and winner of the 2014 New Statesman SPERI Prize in Political Economy and the 2015 HansMatthöfer-Preis. Mazzucato has advised policymakers around the world on how to deliver 'smart', inclusive and sustainable growth. In 2013 she was named as one of the ' 3 most important thinkers about innovation' in the New Republic.

Dr. Gregor Semieniuk is a Lecturer in Economics at SOAS, University of London. Before joining SOAS, he was a Research Fellow at the Science Policy Research Unit (SPRU) of the University of Sussex, working on the Horizon 2020 project DOLFINS - Distributed Global Financial Systems for Society. He completed his PhD in economics at the New School for Social Research in New York City, where he analyzed the role of energy in economic growth on the INET-funded project Growth, Distribution and Stability. Gregor currently works on various aspects of the role of energy in economic activity. 